\title{
FURTHER RADIOMETRIC MEASUREMENTS AND TEM- PERATURE ESTIMATES OF THE PLANET MARS, 1926
}

\author{
By W. W. Coblentz and C. O. Lampland
}

\section{ABSTRACT}

The measurement of the radiation from the planet Mars at the 1926 opposition is a continuation of the program of radiometric work on this planet carried on at the Lowell Observatory, Flagstaff, Ariz., at the preceding oppositions of 1922 and 1924.

The telescope used was the 42 -inch Lowell reflector, which is equipped with auxiliary mirrors giving focal lengths of 18,53 , and 80 feet.

The radiometers used were a series of thermocouples in vacuum cells. One thermocouple had receivers only $0.12 \mathrm{~mm}$ in diameter and intercepted only 0.01 of the area of the planetary image. These thermopiles were used in connection with an iron-clad Thomson galvanometer.

By means of a series of transmission screens of water, quartz, glass, and of fluorite, the planetary radiation emanating from the irradiated surface of Mars was resolved into spectral components, whereby it was possible to obtain estimates of the temperature of the planetary surface.

One marked feature of the measurements at the present opposition is the low water-cell transmissions of some of the regions observed; that is to say, the high percentage of the planetary radiation and presumably the high temperature measured. In some instances the water-cell transmissions were as low as 20 per cent.

These radiometric measurements were reduced to temperatures by three independent methods of analysis giving concordant results, showing, as previously observed, that the bright areas were cooler than the adjacent dark areas; that the southern (summer) hemisphere was warmer than the northern hemisphere; that the forenoon side was cooler than the afternoon side of the planet-the exception to this rule being sunset clouds, or a dark area on the east limb irradiated for an hour before coming into view.

The temperature differences between the center of the disk and the limbs (also the poles) appear smaller than previously observed; probably seasonal, being a month after Martian summer solstice instead of a month before as obtained in 1924. In general, temperatures were higher than previously observed, as was to be expected in view of the late summer season.

A conspicuous feature of this year's work was the frequent observation of clouds on Mars which decrease the amount of planetary radiation emitted and give apparently low temperatures.

The following estimates of Martian surface temperatures are given: As viewed on the central meridian, the south polar region, $-10^{\circ}$ to $10^{\circ} \mathrm{C}$; ; south temperate zone, $10^{\circ}$ to $20^{\circ} \mathrm{C}$. (clouds, $-10^{\circ} \mathrm{C}$.) ; center of the disk, 20 to $30^{\circ} \mathrm{C}$.; north tropical zone, $5^{\circ}$ to $15^{\circ} \mathrm{C}$; ; north polar region, $-25^{\circ}$ to $-40^{\circ} \mathrm{C}$.; sunrise limb (after being irradiated for an hour), $-10^{\circ} \mathrm{C}$., no phase, $-20^{\circ} \mathrm{C}$., clouded $-35^{\circ}$ C.; sunset limb (terminator), $-10^{\circ} \mathrm{C}$, no phase, $10^{\circ} \mathrm{C}$, , clouded, $-30^{\circ} \mathrm{C}$. 
I. Introduction

II. Instrumental equipment and methods of observations ........ 240

III. Radiometric measurements of selected regions on Mars._._._._. 244

1. Center of disk

2. Bright and dark areas.-.-_._-_._- 250

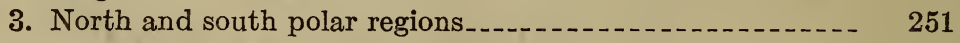

4. East and west limbs_._._._-_._- 253

IV. Temperature estimates..............- 257

1. Planetary temperatures derived from the law of spectral radiation

2. Planetary temperatures derived from the law of total radiation

3. Planetary temperatures derived from a comparison with the moon

4. Accuracy of the temperature estimates.-_-_-_- 265

V. Concluding remarks and summary _..._....... 267

VI. Appendixes_.....

1. Corrections to the stellar radiometric measurements of 1921_ 270

2. Supplemental data on planetary radiation and selective reflection of Mars..... 271

3. Water-cell transmissions of solar radiation _..._-_._...- 275

\section{INTRODUCTION}

For some years the National Bureau of Standards has been conducting investigations of the application of instruments and methods of radiometry to various fields of research. During the past six years the bureau and the Lowell Observatory (Flagstaff, Ariz., elevation 7,250 feet) have been cooperating in a series of astronomical investigations, using these radiometric instruments in combination with the 42-inch Lowell reflector, especially in the study of planetary radiation. The importance of close cooperation of physics and astronomy is evidenced by the great amount of observational material obtained in a comparatively short time. In future work, the results obtained will be greatly enhanced by conducting the radiometric measurements in even closer cooperation than in the past with visual and photographic observations of the planetary surface. This is especially important at certain seasons when the atmosphere of Mars is frequently cloudy, as was the case during October and November of the 1926 opposition. As will be noticed in a subsequent page, the presence of clouds had a marked effect upon the radiometric measurements.

The temperature and the radiation of the surface of Mars are intimately connected with the meteorology of that planet. There are no oceans on Mars, and climatic conditions are no doubt simpler than our own. When it is summer on one hemisphere, and the sun's rays are melting the polar snows, what little vapor exists is traveling 
(probably by diffusion and by strong winds) to the opposite hemisphere to be deposited as snow at that pole, where the temperature is the lowest. This has been observed for years. During the two equinoctial periods the surface is more obscured by clouds or mist.

The measurement of the actual temperature of the surface of Mars does not seem so impressive as is the possibility of observing the variations of the surface temperature with the season. On the earth we find that the summer hemisphere is much warmer than the winter; and when it is summer on the northern hemisphere it is winter on the southern hemisphere. The hottest time on the earth is not at the summer solstice, but a month or so later. By that time the north polar region is at its highest temperature. Furthermore, it is cooler in the morning than in the afternoon, and this condition is affected by clouds.

Similar climatic conditions are observed on Mars. Piecing together the data for the oppositions of 1924 and 1926, all are in agreement in indicating that the southern hemisphere (the summer hemisphere at these two oppositions) of Mars is warmer than the northern hemisphere. The surface temperature rises as the summer advances. It is hottest in the summer hemisphere, at least in the temperate and frigid zones of Mars, not at the time of the Martian solstice, but a month or so later, because of the accumulation of heat, as observed on the earth.

Furthermore, the morning side (sunrise) is cooler than the afternoon, except when there are afternoon clouds to obscure the surface and prevent the surface radiation from escaping. Under these conditions the morning side of the planet has been observed hotter than the cloud-covered sunset edge, but an hour later conditions were just the reverse. Observations on the escape of nocturnal radiation from the earth show that but little cloudiness is required to prevent the escape of radiation from the surface through the atmosphere into space. Owing to the great amount of water vapor present at all times in the earth's atmosphere, even on a cloudless day, the outgoing radiation from the thermopile to the sky is practically zero at sea level, for air mass, 1 ; and also for a 7,000-foot altitude when the air mass is greater than 2. Similarly, though to a less marked degree, clouds on Mars prevent the escape of heat rays from the surface into space. This is indicated by the high transmission of the radiation through the water cell and other screens used, whereas, on other nights, these same localities on the surface of Mars give the normal (low) water-cell transmissions; that is, the normal radiation and normal surface temperature. Occasionally spots are observed which are so warm that the question arises whether this is owing to some thermochemical action; though the lack of clouds would seem to negative such an assumption. 
As already stated, this mapping of hot and cold spots indicating the meteorological conditions on the surface seems more impressive than the actual temperature determinations. It shows the progress made in planetary radiometry, and indicates that the time has come for the active cooperation of photographic, visual, and radiometric methods of observations to determine when these cold areas are caused by clouds and when they are due to the low temperature radiation from the bright areas, which are cooler than the dark areas on the planetary surface. For it is to be understood that the thermocouple does not readily distinguish clouds from cold areas on the surface of Mars. On the other hand, it was observed years ago that the photographic plate will detect Martian clouds that are wholly invisible to the eye.

The principal interest in the opposition of Mars this year was to obtain one more check on the previous temperature estimates, especially on the east and west limbs of this planet; for about 13 years will elapse before there will be another equally favorable opportunity for radiometric measurements, and the present series was the culmination of the preliminary measurements begun during the Martian opposition of 1922. After the completion of the measurements 1 in September, 1924, two of the best vacuum thermocouples and the ironclad Thomson galvanometer were left in place in the Lowell Observatory, and the observations were continued throughout the subsequent three months by Lampland. ${ }^{2}$ All these data, when published, should prove useful in showing the great variation in temperatures with the seasons on Mars.

Similarly, the extensive series of radiometric measurements on Mars obtained by Lampland during the past summer, combined with what we observed in collaboration during the present opposition and what he expects to obtain subsequently, using the same apparatus, should form an interesting record of climatic conditions extending over a much longer period than previously observed.

\section{INSTRUMENTAL EQUIPMENT AND METHODS OF OBSERVATIONS}

After four years of good service the thermocouples in vacuum container No. 11 had but recently ceased to function. A new set of thermocouples and a new rock-salt window were, therefore, provided, forming vacuum cell No. 15 used in the present work. The diameters of the receivers of one of these thermocouples were only 0.12 and $0.14 \mathrm{~mm}$, respectively (the smallest yet tried), and at the 80 -foot focus the smaller intercepted only 0.05 of the diameter of

1 Coblentz and Lampland, J. Franklin Inst., 199, p. 785; 200, p. 103; 1925.

2 Lampland, Pop. Astron., 34, p. 6201926. 
the planetary image. A difficulty with such a small receiver is in painting the whole surface uniformly with lampblack, which, on drying, has a tendency to recede from the edge of the metal disk. The thermocouples in vacuum mounting No. 12 were readjusted and a new quartz tube containing fresh calcium provided.

In addition to these two mountings, Nos. 11 and 12, which had been left at Flagstaff, there was carried from Washington vacuum container No. 14 (the old container No. 13 of 1924) with a new rocksalt window and with new thermocouples having receivers $0.22 \mathrm{~mm}$ in diameter; also the old mounting, No. 7, containing the two thermocouples used in 1914, which are still in good condition in spite of one trip to California and four trips to Arizona, totaling over 26,000 miles.

After the first evacuation and closing of the stopcock it required several days to eliminate all the gases that were gradually given off from the walls of the vacuum chamber and from the lampblack receiving surfaces. This residual gas was easily eliminated by heating the metallic calcium. Subsequently the vacuum cells leaked but little. For example, on one occasion mounting No. 14 stood for five days before the yellow fluorescence of the glass, caused by the cathode discharge, became visible. In order to maintain a uniform radiation sensitivity, the calcium was heated and the vacuum rendered nonconducting several hours before beginning the observation; and, as a general rule, the vacuum was still found nonconducting at the completion of the night's observations.

A new suspension was placed in the ironclad Thomson galvanometer. It was constructed so as to have higher air damping than the one previously used. It differed but little in sensitivity from the suspension used in 1924. The telescope scale was at a distance of $2.4 \mathrm{~m}$, and the time of single swing of the suspension usually was three to four seconds, under which condition the galvanometer sensitivity was about $1.4 \times 10^{-10} \mathrm{amp}$.

The telescope used was the Lowell reflector having a maximum aperture of 42 inches, though sometimes reduced to 40 inches. The auxiliary mirrors gave focal lengths of 18,53 , and 80 feet, and at opposition the planetary images of Mars were, respectively, 0.6, 1.6 , and $2.4 \mathrm{~mm}$ in diameter. All the mirrors were freshly silvered and in excellent condition. Thermocouple No. 14-1L, with a receiver $0.22 \mathrm{~mm}$ in diameter, when used at the 80 -foot focus, intercepted 0.1 of the diameter, or 0.01 of the area of the planetary image. Thermocouple No. 15-1L, having a diameter of $0.12 \mathrm{~mm}$ and as used at the 53 -foot focus, intercepted only 0.075 of the diameter or less than 0.006 of the area of the planetary image.

Although the receivers were considerably smaller in this year's work, owing to various improvements in the radiometric apparatus 
and the higher altitude of Mars, the galvanometer deflections were practically two times those previously observed. Owing to warmer conditions on the poles this year, the deflections were 15 to $16 \mathrm{~mm}$. When the air was steady ("no boiling") the galvanometer was steady to $0.1 \mathrm{~mm}$, and a high accuracy was attainable.

As in previous investigations, ${ }^{3}$ the radiation from Mars was separated into spectral components by means of screens of water, quartz, glass, and fluorite, which procedure enables one to determine the amount of radiation in the spectral regions extending from $0.3 \mu$ to $1.4 \mu, 1.4 \mu$ to $4.1 \mu, 4.1 \mu$ to $8 \mu, 8 \mu$ to $12.5 \mu$, and $12.5 \mu$ to $15 \mu$. The new ultra-violet transmitting glass, Corning G980A, which, like pyrex, has quite a sharp cut-off at $3 \mu$, should prove useful in future work.

Two screens of glass 0.085 and $0.16 \mathrm{~mm}$ in thickness were tried this year, but they did not disclose any difference in the radiation at $6 \mu$ to $8 \mu$ greater than the errors of observation.

The selection of the quartz and the glass screens in 1924 was fortunate. For, as anticipated, it enabled us to study the variation in transparency of the atmosphere at $4 \mu$ to $8 \mu$ with variation in humidity and in air mass. There are some indications that in spite of the large errors of observation it may prove to be a reliable test of the presence of water vapor in the upper atmosphere, in contrast with a wet and dry bulb thermometer which gives an indication only of the vapor pressure of its immediate surroundings.

In this year's measurements all the screens showed a lower transmission; that is to say, a greater amount of infra-red planetary radiation, than observed in 1924 . This is owing, no doubt, to the much higher altitude of Mars and consequently the decreased terrestrial air mass and absorption of infra-red radiation. This increased transmission is especially noticeable in the spectral region of $4.1 \mu$ to $8 \mu$ as disclosed by the observations through the quartz and glass screens.

In the measurements of 1924 the thermocouple was horizontal as shown at $A$ in Figure 1, and the method of observation consisted in making all the measurements upon one spot, using all the screens, before selecting a new region. When using the $U$-shaped thermocouple and setting the left and the right hand receiver upon the same region on the planetary image, any unequal heating of the intervening wire was eliminated. When using the straight-wire thermocouple horizontally, the thermojunction receiver and intervening wire were exposed symmetrically on the north and the south polar regions. But in the settings on the east and the west limbs a little more of the intervening wire might be exposed to radiation in

a Coblentz, B. S. Sci. Papers, Nos. 438, 460, and 512. Coblentz and Lampland, J. Franklin Inst., 199 and $200 ; 1925$. 
one case than in the other. Although the wire had been tested for homogeneity, and although the high reflecting power prevented heating by absorbing infra-red rays (also the measurements with the U-shaped thermocouples showed no difference) in this year's work the measurements on the east and on the west limb were made with the thermocouple in both the horizontal and in the vertical position as shown at $A$ and $B$ in Figure 1. No difference was observed in the results, as was to be expected in view of the fact that we were dealing with ratios instead of absolute values of galvanometer

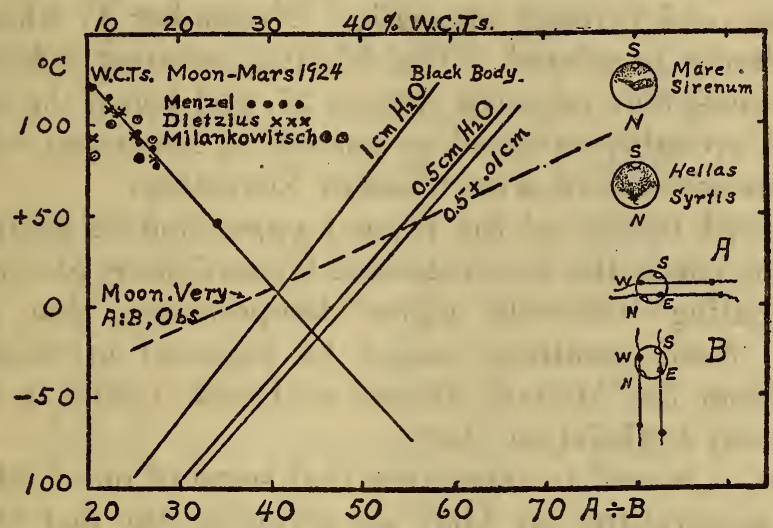

FIG. 1.-Planetary temperatures as derived from the ratio $(A \div B)$ of the 'spectral components of planetary radiation, and from the water-cell transmissions (W. C. Ts.). Also illustration of markings on the Martian surface and methods of setting the thermocouples on the planetary image

deflections. However, it seemed necessary to make the test in order to satisfy the most exacting critic.

In order to save time and to avoid possible slight differences in focus when using the water cell, instead of completing all the measurements on one spot before selecting another, in this year's work a series of measurements was made alternately on the north and south poles (or on the east and west limbs) without the water cell; then a series with the cell interposed; then another series without the cell. This required the observation of 24 to 30 galvanometer deflections. In the tests on the east and west limbs during one evening (October 27) two such sets of measurements of 56 and 66 galvanometer readings were made. This should give a better average value than a single momentary impression upon a photographic recording device. $46937^{\circ}-27-2$ 


\section{RADIOMETRIC MEASUREMENTS OF SELECTED REGIONS ON MARS}

The outstanding feature of this year's work is the measurement of the radiation from clouds and from different parts of the surface of Mars. The radiometric measurements recorded in this paper were made on 15 nights during October and the first week in November. Hence, they cover a period when there was a bright phase on the east limb (which was irradiated an hour or more before turning into view) through perigee (October 28) when the planetary image was a maximum, and through opposition (November 4) when the disk was completely irradiated. The Martian summer solstice on the southern hemisphere occurred August 25, and hence the south polar region had probably attained or passed its maximum temperature when our measurements were made in November.

One marked feature of the present opposition as compared with the previous one is the low water-cell transmissions (down to 20 per cent) indicating relatively higher temperatures than heretofore suspected. Such conditions might be expected in measuring the radiation from the Mohave Desert or Death Valley in California, but they seem doubtful on Mars.

However, it is well to remember that some of our doubts regarding high temperatures on Mars are owing to the fact that we are accustomed to make comparisons in terms of air temperatures as we do on this earth. As we all know, the temperature of the air on a hot day rises to $25^{\circ}$ or $30^{\circ} \mathrm{C}$., but we overlook the fact that under these conditions the temperature of the solid dry surface may be up to $40^{\circ}$ to $50^{\circ} \mathrm{C}$.

On Mars we are measuring the radiation and temperature chiefly of those regions on the solid surface that are the most intensely irradiated by the sun. The shadowed areas and the highly rarefied, practically moisture-free air contribute only an imperceptible amount to the radiation emanating from the Martian surface. The data obtained with the various screens are given in Tables 1 and 2. 


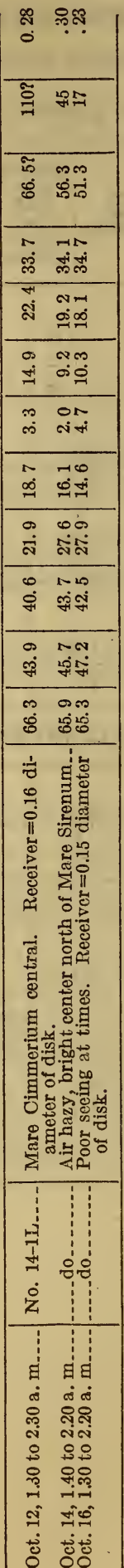

เด รูกิกลก

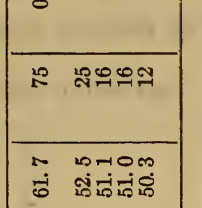

000010

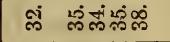

ㄱ. Non

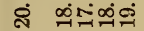

๓

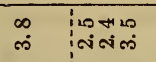

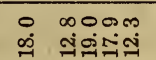

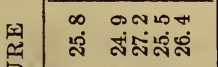

$n$ Than

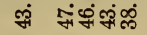

मी

का म0न

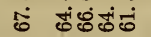

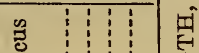

楽

용

क

梂

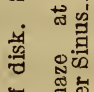

वृ

5.

总需密

:

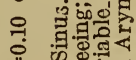

il.

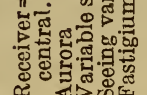

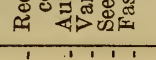

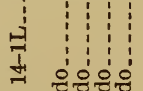

-

\begin{tabular}{l:l:} 
& $\mathbf{z}$ \\
\hline
\end{tabular}

घ घ घ

का का को

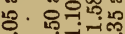

की

용

(ิ

สิ สีลิลัติ

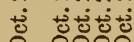

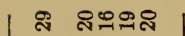

눈 ํำ

$\infty$ กิก

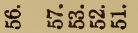

- nNisus

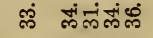

0 OONR

ஹ

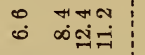

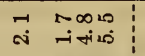

ก 000nis

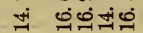

00000

ต ลืลส

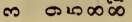

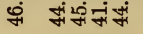

r.

- Nm20

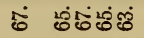

1 $15:$

-

噤

$\div$ :

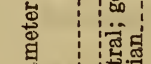

今

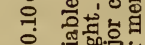

II

\& 300.09

ณ

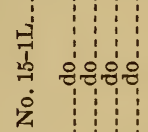

घ $\quad$ a

$\infty$ घ

$\leadsto$ :

ษ่

웅요

두 สণํํำ

มี

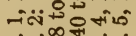

品 
TABLE 2.-Water cell transmissions (W.C.Ts.) in per cent

[Data are corrected for reflection of radiation by the absorption cell. The temperatures calculated by by interpolation

18.4-FOOT FOCAL LENGTH, 42-INCH APERTURE

\begin{tabular}{|c|c|c|c|c|c|c|c|c|c|c|c|c|c|}
\hline \multirow{2}{*}{$\begin{array}{l}\text { Date, 1926, a. mu, } \\
\text { Mountain stand- } \\
\text { ard time }\end{array}$} & \multirow{2}{*}{$\begin{array}{l}\text { Thermo- } \\
\text { couple }\end{array}$} & \multicolumn{2}{|c|}{$\begin{array}{c}\text { East } \\
\text { limb } \\
\text { (morning) }\end{array}$} & \multicolumn{2}{|c|}{$\begin{array}{l}\text { Midway; } \\
\text { east } \\
\text { limb } \\
\text { and } \\
\text { center } \\
\text { of disk }\end{array}$} & \multicolumn{2}{|c|}{$\begin{array}{l}\text { Equa- } \\
\text { tor; } \\
\text { center } \\
\text { of disk }\end{array}$} & \multicolumn{2}{|c|}{$\begin{array}{l}\text { Midway; } \\
\text { west } \\
\text { limb } \\
\text { and } \\
\text { center } \\
\text { of disk }\end{array}$} & \multicolumn{2}{|c|}{$\begin{array}{l}\text { West } \\
\text { limb } \\
\text { (after- } \\
\text { noon) }\end{array}$} & \multicolumn{2}{|c|}{$\begin{array}{l}\text { South } \\
\text { polar } \\
\text { region }\end{array}$} \\
\hline & & $\begin{array}{l}E \dot{H} \\
\dot{0} \\
\dot{B}\end{array}$ & $0^{\circ}$ & $\begin{array}{l}\dot{8} \\
\dot{0} \\
\dot{3}\end{array}$ & 0 & $\begin{array}{l}E \dot{H} \\
\dot{0} \\
\dot{\beta}\end{array}$ & $0^{\circ}$ & $\begin{array}{l}E \dot{H} \\
\dot{0} \\
\dot{B}\end{array}$ & $0^{\circ}$ & $\begin{array}{l}\dot{H} \\
\dot{0} \\
\dot{3}\end{array}$ & : & $\begin{array}{l}E \dot{0} \\
\dot{0} \\
\dot{B}\end{array}$ & $0^{\circ}$ \\
\hline $\begin{array}{l}\text { Oct. } 7 \text { : } \\
2 \text { to } 2.45\end{array}$ & No. 14-IL.. & 35.9 & & & & 28.1 & $\left\{\begin{array}{l}10^{*} \\
3\end{array}\right.$ & & & 329 & $\begin{array}{r}-0 \\
2\end{array}$ & & \\
\hline $\begin{array}{l}\text { Oct. } 10: \\
1 \text { to } 1.30\end{array}$ & No. 14-1L.- & $\left\{\begin{array}{l}30.2 \\
28.9\end{array} \mid\right.$ & & & & 29.8 & 4 & & & 28.6 & oe & & \\
\hline 2.50 to 3.10 & .....do & $\mid \begin{array}{r}228.2 \\
24.2\end{array}$ & & & & & & & & 29.5 & & & \\
\hline $\begin{array}{l}\text { Oct. } 11 \text { : } \\
2.15 \text { to } 2.35 \ldots\end{array}$ & -............ & 31.6 & & & & 27.9 & $\left\{\begin{array}{l}14^{*} \\
10\end{array}\right.$ & & & 31.9 & & & \\
\hline 2.45 to 3.30 & .....do & 31.6 & & & & 29.6 & $10 \mathrm{e}$ & & & 30.1 & & 27.6 & 11 \\
\hline
\end{tabular}

53.3-FOOT FOCAL LENGTH, 42-INCH APERTURE

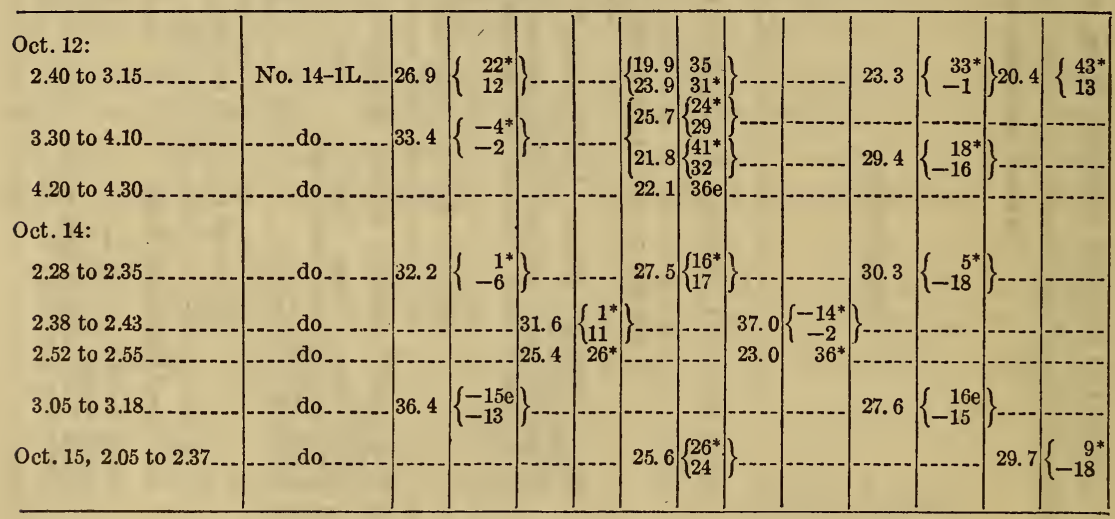




\section{of the total radiation emanating from isolated regions on Mars}

Menzel are marked with an asterisk (*); the unmarked values are by Lampland, and the values obtained are marked $e]$

18.4-FOOT FOCAL LENGTH, 42-INCH APERTURE

\begin{tabular}{|c|c|c|c|c|c|c|}
\hline \multicolumn{2}{|c|}{$\begin{array}{l}\text { Midway; } \\
\text { south pole } \\
\text { and center } \\
\text { of disk }\end{array}$} & \multicolumn{2}{|c|}{$\begin{array}{l}\text { Midway; } \\
\text { north } \\
\text { pole and } \\
\text { center of } \\
\text { disk }\end{array}$} & \multicolumn{2}{|c|}{$\begin{array}{l}\text { North } \\
\text { polar } \\
\text { region }\end{array}$} & \multirow{2}{*}{ Remarks } \\
\hline $\begin{array}{l}E \dot{E} \\
\dot{0} \\
\dot{3}\end{array}$ & 0 & $\begin{array}{l}E \dot{~} \\
\dot{0} \\
\dot{B}\end{array}$ & 0 & $\begin{array}{l}E \dot{~} \\
\dot{E}\end{array}$ & $0^{\circ}$ & \\
\hline & 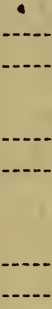 & & & 37.1 & -16 & $\begin{array}{l}\text { Receivers horizontal, intercepting about } 0.45 \text { the diameter of the } \\
\text { disk image of Mars. } \\
\text { Receiver } 1 \mathrm{R} \text { is slightly larger than } 1 \mathrm{~L} \text {, intercepting more of disk and } \\
\text { giving lower W. C. Ts. } \\
\text { Receivers vertical (that is, rotated } 90^{\circ} \text { ). Air boils; image unsteady. } \\
\text { Dark phase on west limb. Syrtis Major rotating into view on east } \\
\text { limb, which is dlready heated for an hour and is hotter than west } \\
\text { limb. } \\
\text { East limb appears dark; same temperature as west limb. } \\
\text { Center of disk observed at } 3.45 \mathrm{a} . \mathrm{m} \text {. }\end{array}$ \\
\hline
\end{tabular}

53.3-FOOT FOCAL LENGTH, 42-INCH APERTURE

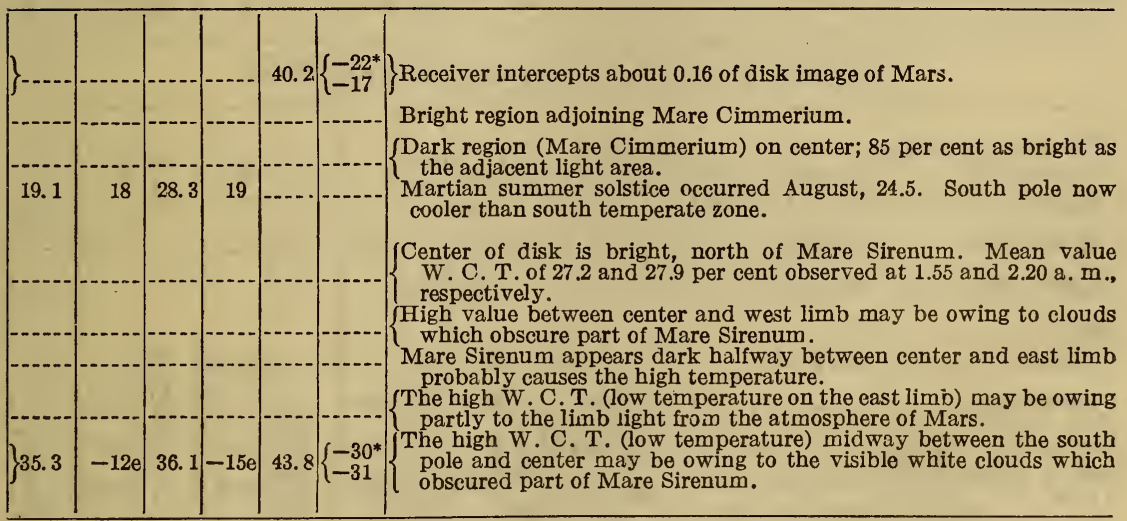


TABLE 2.-Water cell transmissions (W. C. Ts.) in per cent of the 80-FOOT FOCAL LENGTH, 40-INCH APERTURE

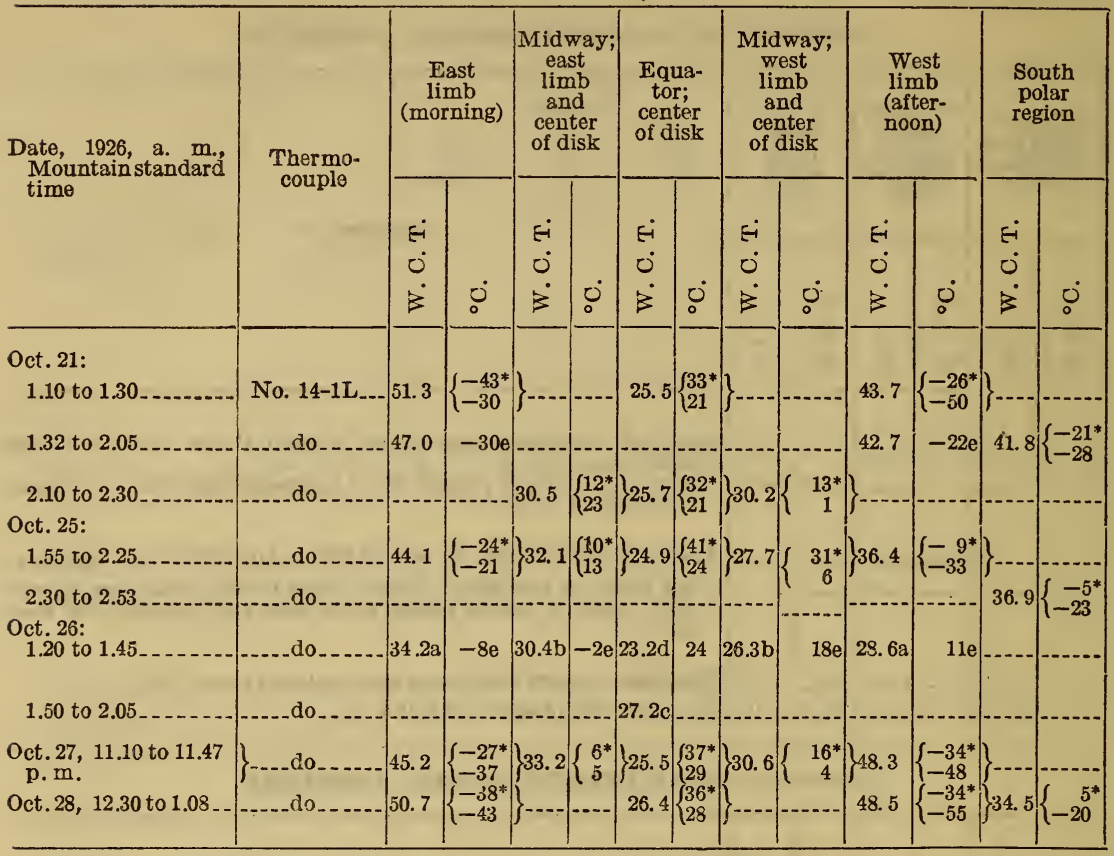

53.3-FOOT FOCAL LENGTH, 42-INCH APERTURE

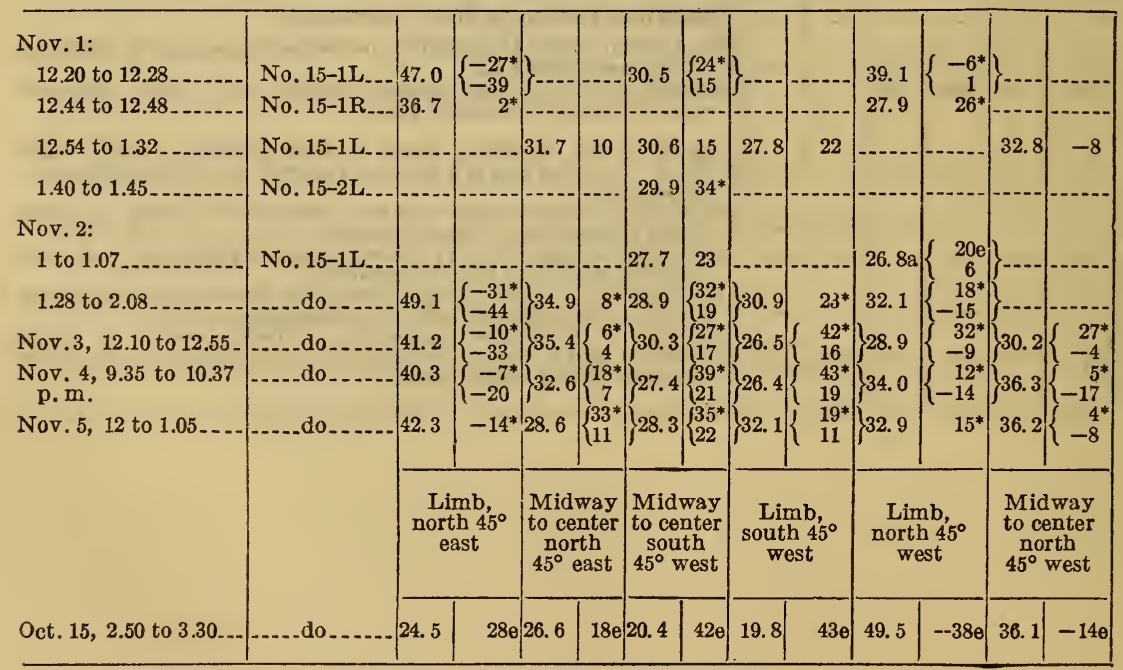


total radiation emanating from isolated regions on Mars-Continued

80-FOOT FOCAL LENGTH, 40-INCH APERTURE

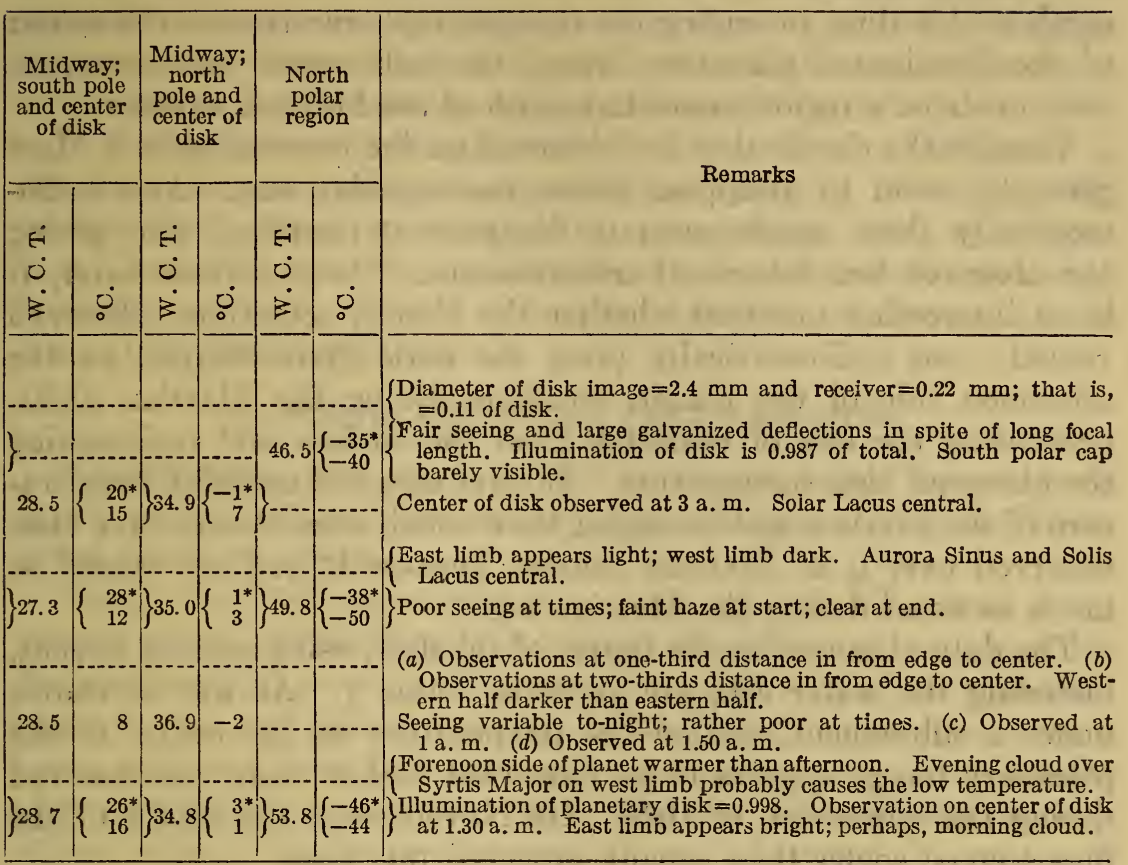

53.3-FOOT FOCAL LENGTH, 42-INCH APERTURE

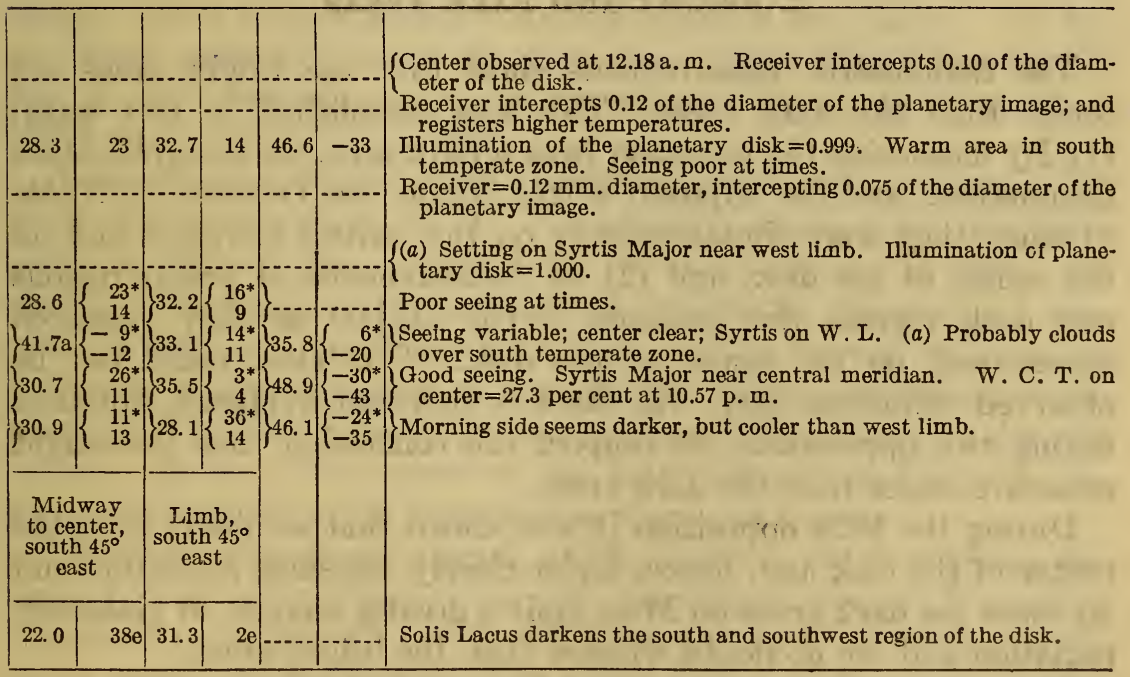




\section{CENTER OF THE DISK}

Owing to the manner in which the south pole was tilted toward the earth at this time, in setting the thermocouple receiver on the center of the illuminated planetary image, the radiometric measurements were made on a region somewhat south of the Martian equator.

Visually the clouds that are observed on the morning side of Mars generally seem to disappear under the noonday sun. Also radiometrically these clouds seem to dissipate at noonday, thus giving the observed low water-cell transmissions. On the other hand, it is an interesting question whether the clouds, sometimes observed visually and radiometrically (over the dark Syrtis Major) on the afternoon side of the planet, continue during the Martian night, preventing the loss of radiation from the surface and maintaining the observed high temperature. In that case the noonday temperature of the Syrtis might be higher than usual, after clouds have been observed over it at Martian sunrise, because it had not cooled so much as usual during the Martian night.

The data obtained on the center of the disk, using various screens, including the water cell, are given in Table 1. As will be shown under a subsequent caption the temperature on the center of the planetary image appears to be somewhat higher than was observed during the opposition of 1924 . On November 1 the center of the disk seemed cooler than usually observed this year.

\section{BRIGHT AND DARK AREAS}

The radiometric measurements show that the bright areas are cooler than the dark areas. This was established in two ways: (1) By measuring the radiation from a dark area, for example, Mare Cimmerium, and the adjacent bright region (see October 12, Table 2) when they were simultaneously on the central meridian and on the center of the disk, and (2) by measurements of bright regions and dark regions (for example, Syrtis Major) as they appeared successively on the center of the disk. The latter could not be observed simultaneously, but there is sufficient evidence, obtained during two oppositions, to support the conclusion that the bright areas are cooler than the dark areas.

During the 1924 opposition it was shown that as observed in the center of the disk and, hence, under closely the same insolation and air mass the dark areas on Mars emit a greater amount of planetary radiation and are no doubt warmer than the bright areas. ${ }^{4}$

These observations were verified in a series of measurements made on October 12, 1926. The particular regions measured radiometrically were the dark area called Mare Cimmerium and the adjacent 
bright region when they were on the central meridian. As judged from the radiation transmitted through the water cell the dark area was about 85 per cent as bright as the adjacent light-colored area; the water-cell transmissions being 21.8 and 25.7 per cent, respectively, equivalent to a difference in temperature of $10^{\circ}$ to $15^{\circ} \mathrm{C}$.

If this difference in temperature is the result of a difference in elevation then according to calculations made by Pickering ${ }^{5}$ the cooler bright-colored areas (deserts) are, perhaps, 7,000 feet higher than the dark areas. So small a difference in elevation would escape detection visually. Lowell estimated 2,000 to 3,000 feet as the limit of elevations on Mars.

\section{NORTH AND SOUTH POLAR REGIONS}

Measurements were made on the north and south polar regions and at points halfway between the poles and the center of the illuminated planetary image.

During the 1926 opposition the south pole of Mars was tilted toward us and the north pole was tilted away from us, so that when the thermocouple receiver was set on the north edge of the planetary image it was not placed upon the north pole (winter), but upon a region quite far down into the north temperate zone. This explains why such high temperatures were observed when setting upon a region midway (in the north tropical zone) between the center of the brightly illuminated disk and the northern edge of the planetary image, which is some distance from the pole of the planet. As will be shown presently, when the dark area, Syrtis Major (see fig. 1), was on the meridian, the north temperate zone appeared to be as warm as the center of the disk.

A conspicuous feature of this year's measurements on Mars is the water-cell transmission (W. C. T.), which is much lower (the temperature higher) than observed on the polar regions in 1924. As already mentioned, one reason for this is that the observations were made a Martian month after summer solstice instead of a month before, as in measurements two years ago. The temperature of the south pole probably had attained or passed the maximum for the season. In fact, from some of the measurements it might be interpreted that the south polar temperature was waning.

Sometimes the measurements at the point halfway between the south pole and the center of the disk (see observations of November 3) indicate a higher W. C. T. $=41.7$ per cent (a lower temperature) in the south temperate zone than at the center of the disk. Again, on some other date (see Table 2, October 15), the water cell trans-

${ }^{3}$ Pickering, Pop. Astron., 33, p. 443; 1925. The calculations are based upon our measurements of a temperature difference of 10 to $15^{\circ} \mathrm{C}$. and upon the fact that the temperature drops $1^{\circ}$ per (about) 500 feet increase in elevation. $46937^{\circ}-27-3$ 
mission of the radiation emanating from this midpoint was unusually high, seemingly as the result of a visible cloud over Mare Sironum. As shown in the two illustrations in Figure 1, these lower temperatures might arise from the presence of the bright regions south of Mare Sirenum or the bright area, Hellas, south of Syrtis Major; but the very high water-cell transmissions indicate that, more likely, they are due to (at least augmented by) the presence of clouds.

The temperature of the north tropical zone was higher than observed in 1924, and, as a general observation, the differences in temperature between the center of the disk and the poles, also the limb and the terminator, were not so great as observed two years ago. Whether this is seasonal will require further study.

On the night of November 4 the temperature (W. C. T. $=30.7$ and 30.9 per cent) of the south temperate zone remained constant while the temperature of the point midway between the north pole and the center increased (W. C. Ts. dropped from 35.5 to 28.1 per

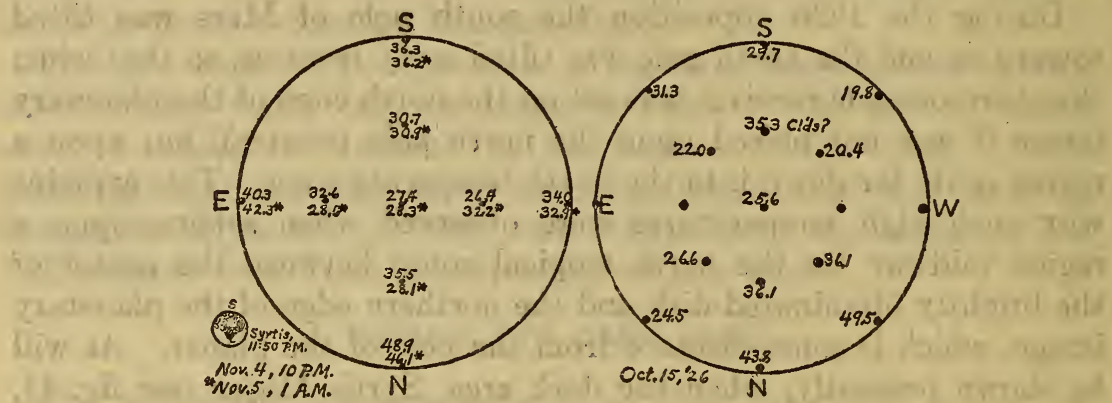

Fig. 2.-Water-cell transmissions (in per cent) observed on different parts of the planetary image of Mars. The higher the observed transmission the lower the surface temperaiture

cent) as the dark Syrtis arrived on the meridian. The north tropical zone then seemed to be hotter than the south temperate zone. The reason for this is obvious from an inspection of the illustration in Figure 1, where it is shown that the dark region, Syrtis, and the bright region, Hellas, are about midway between the center and the poles. The greater absorption of the dark Syrtis compensates for the decreased insolation on the north tropical zone as compared with the lower absorption of, but higher insolation on, the bright Hellas in the south temperate zone.

On this same date (November 4 to 5, see Table 2) a similar variation in temperature was observed on the midpoint of west limb and the center of the disk. Whether this was owing to clouds remains undetermined.

In addition to the measurements across the disk in the northsouth and the east-west direction, one night was devoted to measurements across the disk in the direction from N. $45^{\circ} \mathrm{E}$. to S. $45^{\circ} \mathrm{W}$., 
and from N. $45^{\circ}$ W. to S. $45^{\circ}$ E. (See fig. 2.) These measurements are interesting in showing an unsymmetrical temperature distribution over the disk, especially in the southwest quadrant, which was darkened by the presence of the Solis Lacus. A relatively warm area in the south temperate zone was noted on November 1. (Table 2.)

In a cursory examination of the whole planetary image, warm and cold areas were located on the apparently uniformly illuminated disk, showing that the thermocouple can detect clouds or bright areas not always visible to the eye.

\section{EAST AND WEST LIMBS ${ }^{\circ}$}

This year's measurements show varying temperature conditions on the limbs (and for that matter on other parts) of the planetary disk. As a general rule, we found the forenoon side of the planet cooler than the afternoon side. But there were exceptions, such as, for example, on October 10; at 1 a. m. the east (sunrise) limb had the same temperature as the west limb (terminator). Two hours later when the dark area (Syrtis Major) was rotating into view, the east limb, after one and a half hours' exposure to the sun, was hotter than the corresponding region on the terminator, on the evening side, as was to be expected in view of the high absorption and long preheating before measurement.

At 11 p. m., October 27, when a white cloud was overhanging the disappearing Syrtis under an evening sun, the temperature of the west limb was lower than the east limb. Two bours later $(1 \mathrm{a}$. m., October 28), when the sunrise limb was unusually bright (an indication of clouds), the temperature of the east limb was apparently considerably lower than the (west) sunset limb. The term "apparently" is used because we were evidently measuring the radiations from an effective radiating layer situated at some distance above the solid surface.

One night (October 11) when the east (sunrise) limb appeared dark it had the same W. C. T. and presumable the same temperature as the west limb, and on another date (1 a. m., November 1) when the Syrtis was near the west limb the temperature was higher than on the center of the disk. On November 4, with excellent seeing and the dark Syrtis on the central meridian, and the east and west limbs apparently of the same brightness, the east (sunrise) limb was the cooler. This is based on three sets of observations, totaling 56 readings during about 25 minutes. Two hours later, November 5, a

8 For simplicity in recording the data obtained with the various combinations of auriliary mirrors whereby the cardinal points were frequently inverted and reverted, we formed the habit of designating the sunrise limb, "east," and the sunset limb, "west." In this respect we have unintentionally violated a precedent of half a century of astronomical terminology, whereby the west limb of the moon, of Mars, ctc., is sunrise and the east limb is sunset. Acknowledgment is due to Prof. W. H. Pickering for calling attention to this inconsistency. 
set of 66 readings extending over a period of 20 minutes showed that the east (sunrise) limb continued to be cooler than the west limb although it then appeared to be the darker visually. These watercell transmissions on various parts of the planetary image are depicted in Figure 2.

The numerous drawings by various observers show that it is quite difficult to find two regions having the same general physical conditions (absorptivity), one on the east limb, the other on the west limb, and the two in the same latitude. As already mentioned, it requires great familiarity with the surface features of the planet in order to make the selection, especially when there is poor seeing. The simple sketches illustrated in Figure 1 show some of the difficulties experienced with the varying features of Mars.

In spite of these variations in surface brightness, the presence of clouds and irradiation of the east limb for more than an hour before measurement, the prolonged series of measurements of both 1924 and 1926, made on the limbs, and on points halfway between the limbs and the center of the Martian planetary image, indicate, as a general rule, lower temperatures on the sunrise limb than on the sunset limb. This is apparent in all our measurements using the different focal lengths; that is, wide and narrow integrations over the planetary surface.

Although such a condition is to be expected, the observed large temperature difference between the limbs of Mars raises the question of the extent of an absorbing and heat-retaining atmosphere, and, perhaps, the presence of a little more water vapor than the spectroscope has yet shown. But the possibility of the spectroscope being able to decide this particular question may, perhaps, be overestimated, for as sometimes used it gives average values of narrow strips across the whole disk, whereas the above discussion relates to the limbs and poles of the planet. ${ }^{7}$ When we have more extensive spectroscopic data on the limbs and on the clouds, we will be in a better position to judge the matter. ${ }^{8}$

Of course, the presence of some water vapor and an atmosphere is admitted; and even though the radiometric drift curves may not show temperature differences on the east and west limbs, their form seems to deviate sufficiently from the true cosine curve to permit the interpretation that the temperatures at sunrise and at sunset are lower than would be the case if the planet had no atmosphere whatever to reduce the incident light. ${ }^{9}$

\footnotetext{
7 Very, Lowell Obs. Bull. No. 65 , found that the spectrograms taken by V. M. Slipher in 1914 showed a much greater amount of water vapor absorption over the polar region (melting snow or cloud) than over the equator.

${ }^{8}$ In this connection it would be interesting to obtain some spectrograms of the light reflected by terrestrial clouds.

- Ann. Report of Director of Mount Wilson Obs., Carnegie Inst. of Washington, Yearbook No. 24, p: 104, 1925.
} 
It is relevant to add that no doubt the time will come when a useful application can be made of these data regarding clouds and the temperature differences of bright and dark areas in arriving at some reliable estimate of the night temperature on Mars. From a comparison of the W. C. T. measurements on the east and west limbs of Mars on October 28 it appears that the clouds on the west limb were probably thicker or denser than on the east limb. This interpretation follows from the much lower temperature than the average on the west limb as compared with similar observations on the east limb.

As already mentioned, it is desirable to have close cooperation of photographic and visual observations with the radiometric measurements, especially during the seasons when there is frequent cloudiness of the morning and evening atmosphere of Mars. This cloudy condition occurred during the month of October and November of the 1926 opposition, and is probably the cause of the rather frequent observation of warm and cold areas; for example, the cold spot midway between the sunset limb and the center of the disk on November 4 to 5 , already mentioned under the preceding caption.

The observation of cold areas (ascribable to clouds) is not confined to this year's measurements. A similar cold area was observed on the midpoint of the west (sunset) limb and the center of the disk on September 12, 1924. The temperature was so low, in comparison with that of the west limb and the center of the disk, that the cause was ascribed to clouds instead of a bright area on the solid surface.

In concluding this discussion it is of interest to consider the data statistically. The conclusions arrived at in 1924, regarding the difference in temperature of the east and west limbs of Mars, were based upon 10 sets of water-cell transmissions made on the limbs. In two of the sets (August 2 and 6) the per cent transmissions were closely the same, but this no doubt was owing to the fact that the east limb came into the sunlight over an hour and a half before it was visible to the observer. In other words, not taking into consideration the large phase angle and consequent preheating of the east limb before measurements were made, only 20 per cent of the 1924 observations were contrary to expectation. If we consider only the 7 sets, made when there was practically no phase on the east limb, there is no disagreement between the observations and expectation.

In this year's measurements there were 22 sets of water-cell observations on the east and west limbs. Of this number, 2 sets of observations indicated practically the same temperatures on the two limbs. Owing to cloudiness on the limbs 3 sets indicated lower temperatures on the sunset limb; and a total of 17 sets indicated lower temperatures on the sunrise limb.

In other words, of the 20 sets of observations, made when there was practically no phase, only 15 per cent of the total number were 
exceptions to the general rule that the sunrise limb is cooler than the sunset limb; and this can be accounted for by the presence of clouds. If we exclude cloudy conditions and the two sets of measurements which were made when there was a large phase angle there is no disagreement between the observation and the expectation that the sunrise side is and should be cooler than the sunset edge of Mars.

One important reason for undertaking observations this year was to obtain further temperature measurements on the east and the west limbs of Mars. For, as already mentioned, our previous measurements showed that the sunrise limb of Mars was cooler than the sunset limb of the planet. On the other hand, Pettit and Nicholson $^{10}$ found no difference in temperature on the east and west limbs of Mars.

It is to be noted, however, that they used a receiver $0.2 \mathrm{~mm}$ wide and $0.3 \mathrm{~mm}$ long on a planetary image $1.6 \mathrm{~mm}$ in diameter. The receiver, therefore, intercepted one-eighth of the diameter in the east-west direction, and one-fifth of the diameter in the north-south direction. In other words, the receiver extended well into the southtemperate zone when setting on the center of the planetary image of Mars. The axis of Mars was tilted appreciably ( $36^{\circ}$ in 1926) with respect to the meridian. Hence, in taking drift curves of the right ascension, the thermocouple did not pass directly from east to west across the disk, but passed somewhat from NE. to SW. Hence, on the west limb it would be in a zone of lower insolation than on the east limb, and this would counteract the effect of a higher temperature on the sunset side of the planet.

It is hardly to be expected that drift curves across the planetary disk, taken with a recording device that intercepts but once a certain part of the planetary image, for only a few seconds, will always be in agreement with the average of a series of measurements in which this same part of the planetary image is held under observation for 5 to 10 minutes, during which time 1 to 2 dozen (in one case 56 and 66) settings of the receiver were made and the galvanometer deflections recorded, instead of only a single reading. However, assuming that the two methods give comparable results, we have found that, owing to the presence of dark areas, cloudiness, and water vapor, as this year's measurements clearly show, it is a matter of chance as to what temperature conditions (see fig. 3) will be observed on the limbs of the planet. After one has seen the white cloud patches and bright areas it is not difficult to believe that the unusual radiometric results are caused by the climatic and weather conditions on Mars.

From the foregoing it appears that there is no real disagreement in the observations of 1924 made at the Mount. Wilson and the Lowell observatories. But the conclusions arrived at, from radiometric measurements, will be uncertain unless there is good seeing and unless the observations can be extended over a long period.

${ }^{10}$ Pettit and Nicholson, Pop. Astron., 32, p. 606; 1924. 


\section{TEMPERATURE ESTIMATES}

As pointed out in previous papers it is hazardous to attempt to estimate temperatures from the apparent emissivity of the planetary disk as indicated by the magnitude of the galvanometer deflections. Clouds and the bright areas on the surface of Mars reflect more visible radiation than the dark areas. The total radiation from the dark areas is often as large as that observed from the bright areas. Hence, unless we have some knowledge of the physical conditions of the surface under observation, our interpretations of temperature conditions on Mars may be misleading.

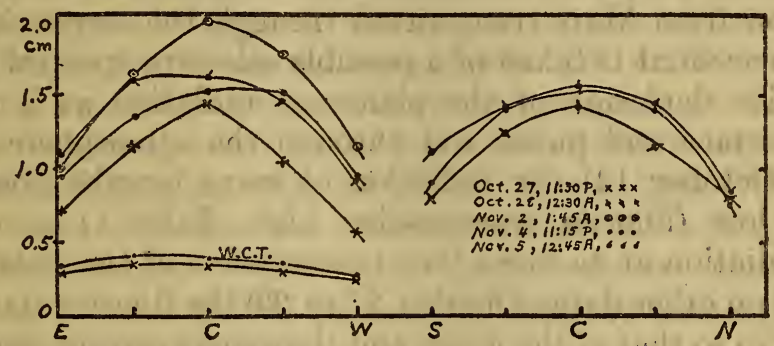

Frg. 3.-Galvanometer deflections showing the intensity of the radiation from different parts of the planetary image of Mars

$E$, east limb; $C$, center of disk; W, west limb (terminator); $S$, south pole; $N$, north polar region.

As shown in Figure 3 the galvanometer deflections observed without the water cell are sometimes larger on the east or sunrise limb (marked $E$ ) than on the west limb $(W)$. Moreover, as these various curves show, the position of the maximum radiation, relative to the center of the disk, varies irregularly, which is no doubt owing to bright and dark areas, or clouds. Hence, this does not seem to be a trustworthy method of determining the distribution of temperatures over the planetary disk. All our interpretations of temperature conditions on Mars are, therefore, based, not upon the galvanometer deflections of the total radiation but upon the transmission values of the screens, which determine to some extent the spectral energy distribution.

The temperatures of the various regions may be estimated from the radiometric measurements by several of the methods previously employed. ${ }^{11}$ First, it is to be noted that the water-cell transmissions are low this year, owing to the decreased air mass $(m=1)$ as compared with an air mass of 1.5 to 2 as obtained in 1924; and also owing to the longer period of insolation of Mars, especially over the South Pole, which had been exposed to the sun continuously for about six months. The measurements with the quartz and the glass screens show a greater amount of infra-red at $4 \mu$ to $8 \mu$ than was

1 Coblentz, B. S. Sci. Papers (No. 512), 20, p. 372, 1925; Popular Astron., 33, p. 310, 1925; Coblentz and Lampland, J. Franklin Inst., 199, p. 785; 200, p. 103, 1925. 
observed in 1924. On the other hand, the transmissions of the fluorite screen are not much lower than previously observed, showing that the region at $4 \mu$ to $8 \mu$ is most affected by changes in air mass and, hence, changes in the amount of water vapor present.

The ratio $(\mathrm{A}: \mathrm{B})$ of the spectral components of the planetary radiation at $8 \mu$ to $12.5 \mu$, and $12.5 \mu$ to $15 \mu$, respectively, as observed with the glass and the fluorite screens, is unusually large. This large ratio would result, at least partly, from the decreased air mass and, hence, the decreased absorption of water vapor, which, as just mentioned, undergoes a greater variation at $7 \mu$ to $9 \mu$ than at $12 \mu$ to $15 \mu$.

Now, all our previous calculations of temperatures are based on the radiation from Mars transmitted through the terrestrial atmosphere. No account is taken of a possible selective spectral emission, or a selective depletion of the planetary radiation as it emanates from the surface and passes out through the atmosphere of Mars. At times (October 12) the radiation of wave lengths greater than $12 \mu$ seems low (fluorite transmission high, Table 1) as compared with the radiation at $4 \mu$ to $8 \mu$ (low transmission of the water cell and quartz) and on other dates (October 27 to 29) the fluorite transmission is low relative to that of the water and the quartz screens, indicating a relatively larger amount of radiation of wave lengths greater than $12 \mu$

It is generally considered that the water vapor is low on Mars, but nothing is known of the amount of ozone and carbon dioxide which are known to absorb greatly, especially $\mathrm{CO}_{2}$ for wave lengths greater than $14 \mu$. Fowle's researches indicate that one-fortieth part of the amount of $\mathrm{CO}_{2}$ actually present in the vertical terrestrial atmospheric column is sufficient to produce complete absorption beyond $14 \mu$.

Owing to the probable small amount of water vapor present the transmission of planetary radiation through the Martian atmosphere at $7 \mu$ to $9 \mu$ would be greatly increased relative to its value at $12 \mu$ to $14 \mu$ where $\mathrm{CO}_{2}$ absorption begins. This might escape detection in 1924 because of the larger air mass, and, hence, the greater terrestrial absorption at $7 \mu$ to $9 \mu$ relative to the absorption at $12 \mu$ to $14 \mu$, which varies but little with air mass. This should increase the calculated values of the ratios $\mathrm{A}: \mathrm{B}$, and be more nearly comparable with the observed values.

The temperature calculations were made on the basis of $0.5 \mathrm{~cm}$ precipitable water in the terrestrial atmosphere and $0.012 \mathrm{~cm}$ precipitable water in the Martian atmosphere, but using the same ozone and $\mathrm{CO}_{2}$ absorption in both atmospheres (atmospheric transmission data from Smithsonian Physical Tables). This increases the calculated value of the ratio $A: B$; but there is still an outstanding selective emission, giving an abnormally high observed ratio of the spectral component radiation at $8 \mu$ to $12.5 \mu(=\mathrm{A})$ relative to the value at $12.5 \mu$ to $15 \mu(=\mathrm{B})$. This means that either the temperatures on Mars are higher than seems possible from other considerations, or 
there is an unusual selective absorption ${ }^{12}$ and emission on Mars that is not accounted for in the calculations.

In estimating temperatures, and especially variation of temperature, of a certain locality with season an uncertainty arises because no allowance can be made for variation of temperature with latitude. On widely differing dates the same thermocouple-receiver intercepts appreciably different areas of the planetary disk. This was not so noticeable this year because of the short duration of the measurements included in the present paper. However, it will require consideration in the complete series of this year's work. It was noticeable in the measurements of 1924, especially when setting on the south polar region. Using a receiver 0.4 of the diameter of the planetary image the water-cell transmission (W. C. T.) was 30 per cent. Using a small receiver which intercepted 0.11 of the diameter of the planetary image of the disk and which could be set within the image of the white polar cap, the W. C. T. was high (73 per cent) indicating a low temperature. However, when the seeing was poor, a slight displacement of the thermocouple receiver gave a much lower per cent transmission, because the receiver intercepted radiation from the temperate zone.

The measurements on the south polar region, made by Lampland after the Martian summer solstice (October 5, 1924) indicated a much lower W. C. T.; that is, a higher temperature than observed by us a month earlier. ${ }^{13}$ As explained in that paper the higher temperature was owing to the longer insolation. Our measurements this year were made after the Martian summer solstice in the southern hemisphere, and, hence, at a time when the temperature was probably up to or past its maximum.

\section{PLANETARY TEMPERATURES DERIVED FROM THE LAW OF SPECTRAL RADIATION}

As pointed out in previous papers, this method, which is new, has commendable features that are not found in the other methods employed for estimating planetary temperatures.

The method of observation consists in separating the planetary radiation of wave lengths $8 \mu$ to $15 \mu$ into two components by means of transmission screens of glass and of fluorite, giving spectral radiation components (A and $\mathrm{B}$ ) of wave lengths $8 \mu$ to $12.5 \mu$ and $12.5 \mu$ to $15 \mu$, respectively.

In order to translate these observations (ratios of the observed spectral radiation components $\mathrm{A}: \mathrm{B}$ ) into temperatures it is necessary to assume that the radiation from the planet has the spectral energy distribution of a black body.

\footnotetext{
12 The recent photographs of Mars, through various colored screens, obtained by Ross (Astrophys. Jour., 64, p. 243; 1926) and Wright (Lick Obs. Bull., No. 389), also those of E. C. Slipher, seem to show the presence of an inextensive but strongly scattering atmosphere.

13 Coblentz and Lampland, J. Franklin Inst., 200, p. 114; 1925.
} 
The procedure followed in calculating ${ }^{14}$ the spectral component radiation at $8 \mu$ to $15 \mu$ consists in plotting the spectral energy curve of a black body at say, $0^{\circ} \mathrm{C}$., as shown in Figure 4, and multiplying the ordinates by the spectral transmission coefficient of the air, using the data given in the Smithsonian Physical Tables for $0.5 \mathrm{~cm}$ precipitable water for the terrestrial atmosphere, and $0.01 \mathrm{~cm}$ for the passage of the rays through the Martian atmosphere as already explained. These data are given in Table 3.

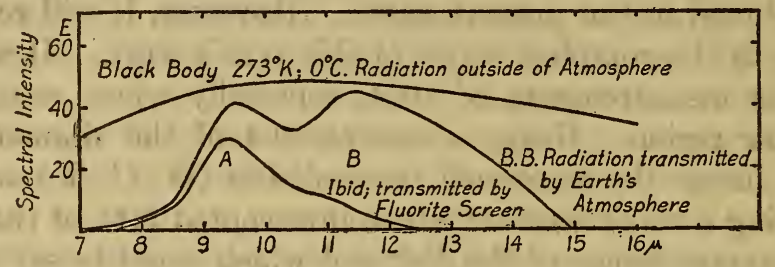

FIG. 4.-Method of calculating the spectral component radiation $(A$ and $B)$ and estimating planetary temperature

TABLE 3.-Transmission percentages of air containing 1, 0.5 , and $0.01 \mathrm{~cm}$ precipitable water; also transmission data of fluorite screen used

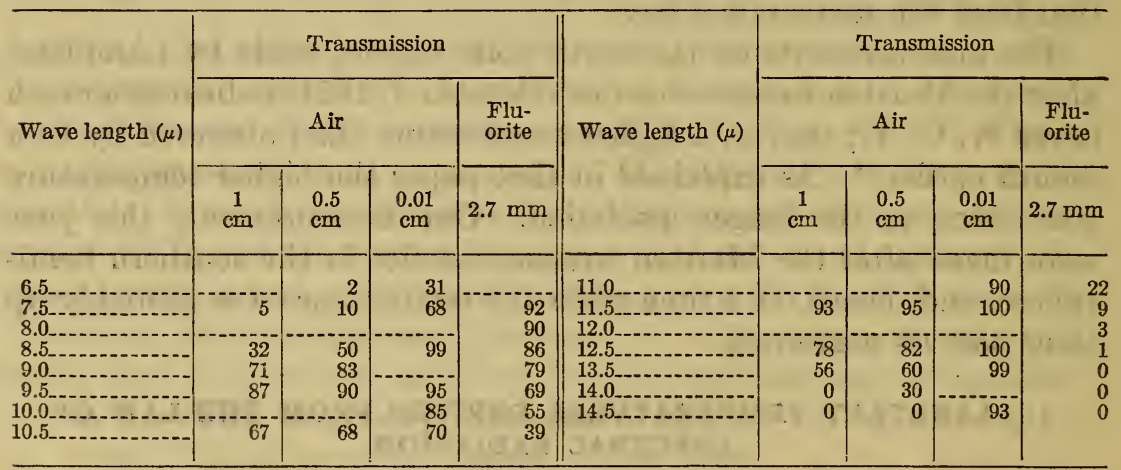

This gives a new curve extending from $8 \mu$ to $15 \mu$ with an indentation at $10.5 \mu$. The ordinates of this curve (which is supposed to be similar to the spectral energy distribution of the planetary radiation, after passing through the earth's atmosphere) were then multiplied. by the transmission factors of the fluorite screen, and the areas inclosed by these curves integrated. The areas under these two curves represent the planetary radiation components extending from $8 \mu$ to $12.5 \mu(=\mathrm{A})$ and $12.5 \mu$ to $15 \mu(=\mathrm{B})$, respectively. The calculated ratios of these two areas A:B vary from 26 per cent at $-23^{\circ}$ C. to 70 per cent at $127^{\circ} \mathrm{C}$. Owing to the rapid variation in the ratios with temperature slight errors in the observation of these ratios have a great effect upon the temperature estimates.

In practice the planetary temperatures are obtained by comparing the observed ratios $\mathrm{A}: \mathrm{B}$ with the calculated values plotted in the 
graph marked "black body $0.5+0.01 \mathrm{~cm}$ " in Figure 1. There is but little difference $\left(6^{\circ}\right.$ to $7^{\circ}$ C. $)$ in the ratios, $A: B$, calculated for 0.5 $\mathrm{cm}$ precipitable water in our atmosphere and the values obtained by including $0.01 \mathrm{~cm}$ precipitable water, but the same ozone and $\mathrm{CO}_{2}$ absorption on Mars as obtains in the terrestrial atmosphere. For example, at $0^{\circ} \mathrm{C}$. the ratios of $\mathrm{A}: \mathrm{B}$ are 47 and 48 , respectively, as calculated by these two sets of transmission data.

The temperatures calculated by this method are given in the column marked 2, of Tables 4 (revised data of 1924) and in the column marked 1 of Table 5 .

Some of the temperature values seem excessively high, especially in the region of the Solis Lacus, where high temperatures were observed in 1924, see Table 4.

TABLE 4.-Mars, 1924

[Comparison of temperatures on the apparent center of the disk as obtained by various methods. Revised from B. S. Sci. Paper (No. 512), 20, p. 378; 1925]

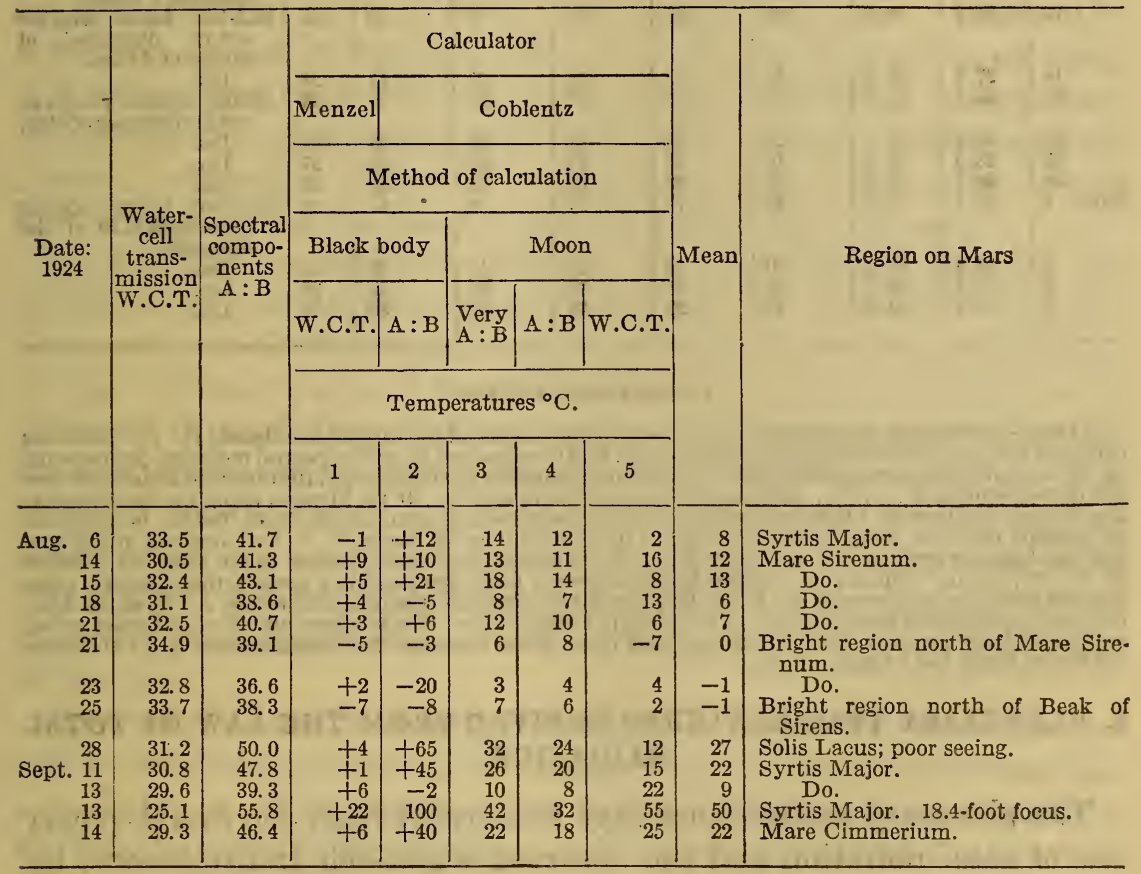

EXPLANATION OF TABLE 4

Mars.-Comparison of temperatures on the apparent center of the disk as calculated: (1) by Menzel by the fourth-power law of black body radiation and the observed Martian water-cell transmissions W: C. Ts.; (2) by Coblentz by the law of spectral radiation and the ratio of the Martian spectral radiation components A : B; (3) by Coblentz by plotting Very's observed lunar temperatures against the observed lunar spectral radiation components A: B and extrapolating to the observed ratios of the Martian components; (4) by calculating the lunar temperatures (Menzel) from the lunar water-cell transmissions, using the fourth-power law, plotting these temperatures against the observed lunar spectral components using the fourth-power law, plotting these temperatures against the observed lunar spectral components A : B, and extrapolating to the observed ratios of the Martian spectral radiation components; and (5)
by Coblentz by plotting the lunar temperatures (which were obtained by Menzel by calculation from the lunar water-cell transmission, using the fourth-power law) against the observed lunar water-cell transmissions and extrapolating to the observed Martian water-cell transmissions. Observations at the 53.3-foot focus; receiver $0.23 \mathrm{~mm}$ in diameter. In the column marked 3, "Very, A : B" the values are true temperatures. All the others are "black body temperaturcs" which are about $10^{\circ} \mathrm{C}$. lower than the true temperatures. 
TABLE 5.-Mars, 1926

[Comparison of temperatures on the apparent center of the disk as obtained by various methods, and calculators; Coblentz (W. W. C.), Lampland (C. O. L.), and Menzel (D. H. M.)]

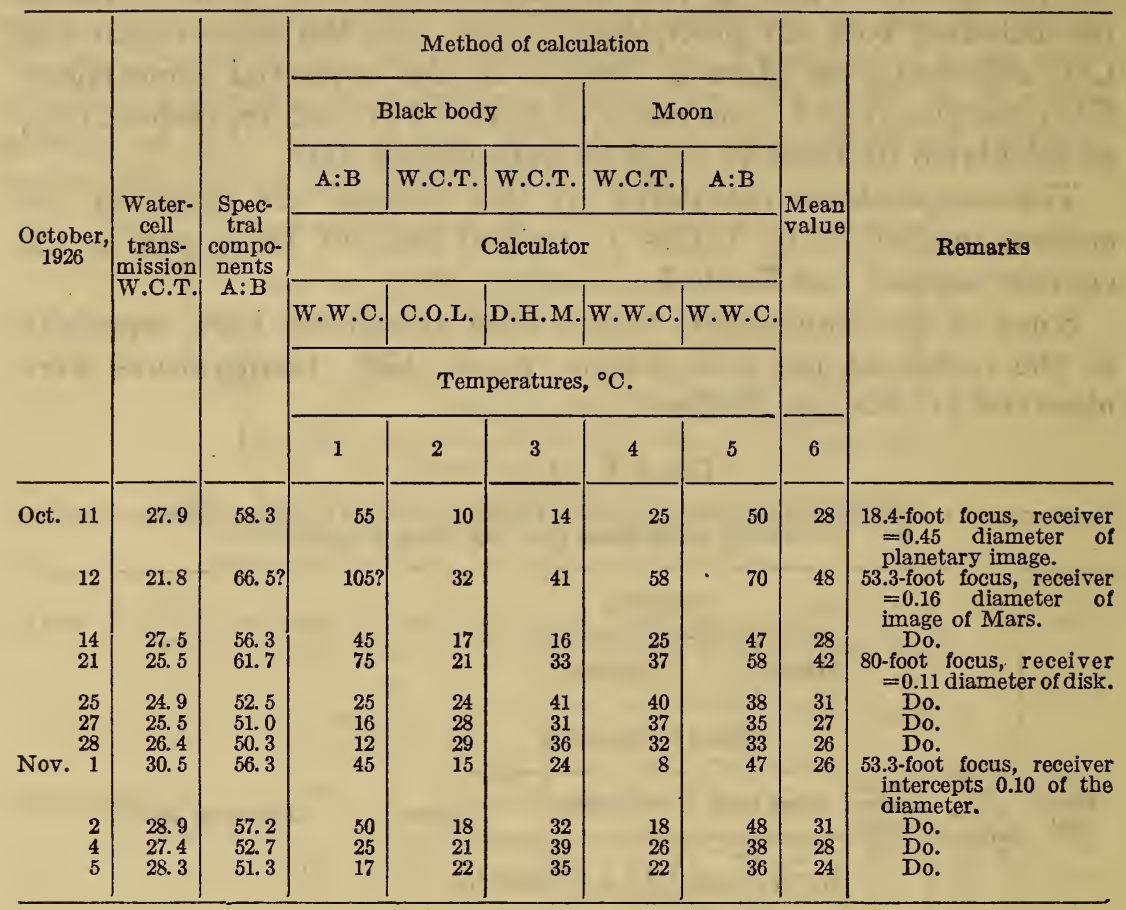

EXPLANATION OF TABLE 5

MARs.-Comparison of temperatures on the apparent center of the disk as calculated: (1) By Coblentz; using the law of spectral radiation and the ratio A: B of the observed Martian spectral radiation components, (2) by Lampland, using the fourth-power law of total radiation of a black body, the observed Martian watercell transmissions, W. C. Ts., and special data on relative albedo; (3) by Menzel, using the fourth.power law of total radiation of a black body and the observed water-cell transmissions, W. C. Ts; (4) by Coblentz by plotting the lunar temperatures (calculated by Menzel from the lunar W. C. Ts. observed in 1924 and the fourth-power law) against the lunar W. C. Ts., Figure 1, and extrapolating to the observed Martian W. C. Ts.; (5) by Coblentz by plotting Very's observed lunar temperatures against the observed lunar spectral radiation components A : B (of 1924) and extrapolating to the observed ratios, A : B, of the Martian spectral radiation components. The values in column 5 , are "true temperatures"; all the other values are "black body temperatures" which are about $10^{\circ} \mathrm{C}$. lower than the "true temperatures"; (6) the mean values are black body temperatures.

\section{PLANETARY TEMPERATURES DERIVED FROM THE LAW OF TOTAL RADIATION}

The planetary temperature may be derived from the fourth-power law of total radiation and the observed water-cell transmissions, by using a method of calculation, the theory of which was first outlined by Russell and the data on planetary radiation, observed by Coblentz and Lampland in 1922, were worked out by Menzel. ${ }^{15}$ Some of the observations on Mars, made by Coblentz and Lampland in 1924, were reduced to temperatures by Menzel ${ }^{16}$ using this method of calcula-

18 Menzel, Ap. J., 58, p. 65; 1923.

16 Menzel, Coblentz, and Lampland, Astrophys. J., 63, p. 177; 1926. 
tion. These temperatures are in good agreement with ours, as shown in the column marked 1 in Table 4.

In view of Doctor Menzel's long experience in using this method of calculating planetary and lunar temperatures it was most efficient to have him make similar calculations of this year's data. His cooperation was therefore invited, and some of the most important water-cell transmissions were submitted to him for calculation and discussion of their bearing on Martian temperatures. ${ }^{17}$ The temperatures calculated by Menzel, using the observed Martian water-cell transmissions of 1926 are given in the column of temperatures marked 3, of Table 5. The data are in good agreement with those obtained by the method of spectral components which, in some instances, show unusually high temperatures.

In the formula used by Menzel there is a factor $X$ which allows for inequalities of illumination of the planet. It is defined as the ratio of the brightness of the region under investigation to the average brightness of the entire surface-the "relative albedo." When only a portion of the illuminated disk is on the thermocouple receiver, $X$ is taken equal to the ratio of the illuminated portion of the apparent disk to the area of the entire disk regarded as circular. Although this factor is somewhat uncertain it enters the equation as the fourth root, thus reducing the errors in the computed temperatures.

In addition to Menzel's calculations, Lampland undertook the derivation of the Martian temperatures from the water-cell transmissions and Russell's formula, modified by using for the relative albedo, $X$ (for different parts of the disk) the galvanometer deflections as observed through the water cell. The "relative water-cell albedo" for any given region is the galvanometer deflection (reduced to a standard galvanometer sensitivity) for that region divided by the mean of all the water-cell deflections taken over the whole disk. The method is admittedly imperfect and incomplete, but it is useful in introducing observational data on the brightness of various parts of the disk.

The calculations by Lampland using the water-cell transmissions and Russell's formula are given in the column of temperatures marked 2 in Table 5. The temperatures derived by these two calculators, working independently, are in as good agreement as can be expected. The temperature data are summarized in Table 2. As for the accuracy of this method of calculation, that will require further study. It is interesting to note that the same water-cell transmissions (on the same region of the planet), represent widely different temperatures. For example, glancing down the column marked "midway, south pole and center of disk" in Table 2, we find that the W. C. T. $=28.5$ per cent represents temperatures ranging from $8^{\circ}$ to $15^{\circ} \mathrm{C}$.

${ }_{17}$ Coblentz, Lampland, and Menzel, Publ. Astronom. Soc. Pacific, 39, p. 97; 1927. 
by one method of calculation; and in the column marked "south polar region," the W. C. T. $=36.3$ per cent represents temperatures of $-8^{\circ}$ and $-17^{\circ} \mathrm{C}$., respectively. Again, at the position on the planet designated "midway, east limb and center," the W. C. T. $=28.6$ per cent represents a temperature of $33^{\circ} \mathrm{C}$., whereas at the point "midway, south pole and center" the W. C. T. $=28.6$ per cent represents $23^{\circ} \mathrm{C}$.

Inconsistencies also appear; as for example in the region designated "midway, west limb and center," where a W. C. T. of 26.5 per cent $=16^{\circ} \mathrm{C}$. and W. C. T. of 27.8 per cent $=22^{\circ} \mathrm{C}$., which is just the reverse of the general proposition that the higher the W. C. T. the lower the temperature.

From this it appears that the determination of the relative albedo, $X$, derived from the galvanometer deflections as observed through the water cell and integrated over the disk, is subject to considerable uncertainty.

Nevertheless, the data calculated by this method are interesting and the average of a large number of calculations may, perhaps, give us more accurate absolute values of temperatures than the unmodified Russell method in which the individual temperature derivations are less variable and, relative to each other, more consistent with the magnitudes of the water-cell transmissions.

\section{PLANETARY TEMPERATURES DERIVED FROM A COMPARISON WITH THE MOON}

Unfortunately no radiometric measurements were made on the moon during the observations on Mars in 1926. However, the lunar temperature is so high (in comparison with that of Mars) that a small change in transmission with air mass does not have a very marked effect upon the water-cell transmissions, and, hence, upon the lunar temperatures. It is permissible, therefore, to use the lunar observations of 1924 in the present work. In the previous paper ${ }^{18}$ dealing with these data the lunar temperatures of Very, of Dietzius, and of Menzel were used in estimating Martian temperatures, and it was shown that they give results which are in agreement with other temperature estimates of Mars.

In the present paper the revised lunar temperatures, ${ }^{19}$ which are about $5^{\circ} \mathrm{C}$. lower than previously calculated ${ }^{20}$ from the observed lunar water-cell transmissions (W. C. Ts.), are plotted in the upper left-hand corner of Figure 1, and by extrapolation to the observed W. C. Ts. of Mars, the corresponding Martian temperatures are

${ }^{18}$ Coblentz, B. S. Sci. Paper (No. 512), 20, p. 381; 1925.

10 Menzel, Coblentz, and Lampland, Astrophys. J., 63, p. 184; 1926.

${ }_{20}$ Also the theoretical calculations of Dietzius (Sitzber. Akad. Wiss. Wien, 132, p. 193; 1924; and of Milankowitsch, Théorie Math. des Phénom. Thermiques Produits par la Rad. Solaire, Paris; 1920. 
obtained. These temperature values are given in the column of temperatures marked 4 of Table 5 .

Another method of obtaining Martian temperatures consists in plotting the observed lunar spectral radiation components, A:B, against Very's ${ }^{21}$ observed temperatures at different ages of the moon and extrapolating to the spectral radiation ratios, $\mathrm{A}: \mathrm{B}$, observed on Mars, as shown in the dotted curve of Figure 1. The temperatures obtained by this method are given in the column marked 5 of Table 5. They are true temperatures, as distinguished from the other values which are "black body" temperatures, which are about $10^{\circ}$ C. lower in value.

This method of obtaining Martian temperatures from observations on the moon yields two sets of values which are in good agreement with the values obtained by the other methods of estimating Martian temperatures.

\section{ACCURACY OF THE TEMPERATURE ESTIMATES}

Prior to our measurements of 1922, and especially those of 1924 , the idea seemed to prevail that it is physically impossible for the temperature of Mars to rise above $0^{\circ} \mathrm{C}$.

No one familiar with the difficulties of measuring temperatures of substances would attempt to assign a definite temperature to the terrestrial surface, 500 miles in diameter, especially when it is heated by absorption of solar radiation.

If the temperature measurements of a substance are made with a thermocouple it is necessary to insert the junction into the material. If the measurement is made with a radiation pyrometer we must have an exact knowledge of the emissivity of the surface of the substance.

Recognizing the futility of defining accurately the temperature of the solid surface of the earth under insolation, why should we expect to define the temperature of the surface of Mars more accurately than $10^{\circ}$ to $15^{\circ} \mathrm{C}$., especially when we do not know the emissivity of the surface?

Because of the lack of knowledge of the constants involved in our calculations our values as derived by any one method may be systematically high or low-the whole level may be above or below the true value.

Hence our aim has been to use every method yet proposed to obtain the planetary temperatures. The conclusions arrived at are based upon four independent methods of analysis. The impressive part of these results is that the estimates are so close to the average values, and that the average values are above the freezing point,

\footnotetext{
"Very, Astrophys. J., 8, pp. 199 and 265; 1898.
} 
showing that, as regards temperature conditions, vegetable life could exist on Mars.

The apparent temperature of a selection region on Mars may be estimated from the amount of radiation transmitted through the water cell or other transmission screens. If the per cent transmission of the total radiation is low it means that the infra-red radiation is high, owing to a high surface temperature. On the other hand, as already mentioned, if the transmission is high the water cell is not a sufficient means to determine whether the observed high value is owing to a low surface temperature or owing to an overhanging cloud or mist of water vapor which prevents the escape of planetary radiation from the surface. Here visual and photographic means must be employed to supplement the radiometric measurements which, in the case of the presence of clouds, do not refer to the surface but to an effective radiation layer situated at some distance above the solid surface.

For example, the disappearing south polar cap, which is evidently of melting snow and ice, indicates that the temperature is $0^{\circ} \mathrm{C}$., whereas, an interpretation of the (high) water-cell transmissions indicates a very low temperature-perhaps down to $-60^{\circ} \mathrm{C}$. This may be true of the north polar region where it is winter, but it does not apply to the melting south polar cap.

Instead of thinking of this difference in temperature at the south pole as an incongruity, it seems to be a pretty good demonstration of the presence of an atmosphere containing water vapor which prevents the escape of planetary radiation.

The greatly increased depth of the atmosphere on the limbs influences the temperature estimates which refer to an effective radiating layer at a greater elevation above the true surface than on the central part of the disk, where the radiation from the surface is less obstructed by the atmosphere. No doubt the estimates of the temperatures on the limbs are too low.

At times one sees the image of Mars surrounded with a brilliant narrow band of "limb light" which comes from the Martian atmosphere, and which probably emits but little if any radiation. Hence, in using these extremely small receivers near the limb uncertainties may arise from setting the thermocouple out, over the edge of the planet, upon the atmosphere, instead of the inner tangent, as was intended. Whether this error is appreciable is uncertain. The most recent estimate of the limb light is by Menzel, ${ }^{22}$ who calculated that the height of the atmosphere at which solar illumination becomes inappreciable is 8 miles on Mars. A receiver 0.1 of the diameter of the planetary image intercepts 420 linear miles. The 8 miles of atmosphere are $(8 \div 420=) \quad 0.02$ of the linear dimension of the 
receiver. From this it appears that the errors in the radiometric settings resulting from the presence of the "limb light" may not be so serious as was first thought.

A conspicuous feature of this year's measurements was the frequent presence of clouds over various parts of the surface of Mars, which affected the radiometric measurements, especially on the east and the west limbs of the planet. However, with each renewed effort new problems are presented, and no doubt in time useful application can be made of the measurements on clouds, perhaps, in obtaining a more accurate knowledge of the temperature on the limbs of the planet. If the clouds, which are sometimes observed over the dark areas (for example, over Syrtis Major) at sunrise, are present during the Martian night, then the temperature of the surface should not fall so low as it does on a clear night. Perhaps the time will come when a reliable estimate can be made of the night temperature of Mars, based upon observations of temperatures at sunrise.

Reference has already been made to variations in temperature depending upon the size of the receiver used. In a refined analysis of temperature conditions a correction will have to be made for latitude, especially when the receiver covers a large part of the disk image. This is quite evident from our measurements of the south polar region made (in 1924) at the 18-foot focus, where the receiver intercepted the white polar cap and part of the adjacent dark areas, and at the 53-foot focus where the receiver was smaller than the image of the polar cap. In the latter case the temperature was the lower and represented more nearly conditions at the pole.

It is relevant to add that some of the observed temperatures are so inordinately high that the question arises whether this is owing to some as yet undiscovered instrumental error or is brought about by some peculiar atmospheric or surface condition on Mars. It is a peculiar situation in that the temperatures are apparently too high, just as the earliest theoretical calculations gave temperatures which seemed to be too low. The question may not be solved without further and prolonged investigation of atmospheric transmission coefficients, etc. Part of the higher temperature condition may, perhaps, be owing to the higher ultra-violet solar radiation, which is increasing with the present cycle of sun-spot activity.

\section{CONCLUDING REMARKS AND SUMMARY}

The present series of radiometric measurements concludes three successful attempts, during the oppositions of 1922,1924 , and 1926 in measuring the radiation and estimating the probable temperature conditions on Mars.

The measurements, made during the Martian opposition of 1922, were of a preliminary nature to try out apparatus and methods. 
From a comparison of the planetary radiation emitted from Mars relative to that of the moon, which has a temperature of $100^{\circ} \mathrm{C}$. or even higher after prolonged insolation, estimates of Martian noonday temperatures of $10^{\circ}$ to $20^{\circ} \mathrm{C}$. were obtained..$^{23}$

This was the first time in the history of astronomy that direct radiometric observations had been made indicating that the temperature of the surface of Mars rises above the freezing point, which result is in harmony with visual observations.

During the opposition of 1924 Mars was at its maximum brilliancy (closest approach to the earth) which permitted the observation of small areas on the image of the planetary disk. The thermocouple receivers, which were $0.23 \mathrm{~mm}$ in diameter, intercepted only about one-eighth of the diameter of the disk of Mars at opposition and permitted the observation of small dark and bright areas, and also the isolated south polar cap. In this respect the thermocouple, with its minute circular receiver, is preeminently adapted for making measurements of the radiation from isolated areas on a planetary image. The bolometer or photoelectric cell can not be so readily adapted to such a problem.

The radiometric measurements on Mars, in 1924, were made on 24 nights extending over a period of 10 weeks, under a wide range of instrumental and meteorological conditions. These measurements showed that, under a noonday sun, the bright equatorial regions of Mars were cooler than the closely adjoining dark regions; that the forenoon side of the planet was at a lower temperature than the side exposed to the afternoon sun; and that the south polar region, where it was summer, was warmer than the north polar region. A seasonal variation in the climate was noted, consisting of a gradual rise in temperature of the south polar region as summer advanced on that hemisphere.

By four independent methods of attack estimates of Martian temperatures ${ }^{24}$ were obtained as follows: Bright areas $-10^{\circ}$ to $5^{\circ} \mathrm{C}$.; dark areas $10^{\circ}$ to $20^{\circ} \mathrm{C}$; north polar region $-70^{\circ} \mathrm{C}$.; south polar region $0^{\circ} \mathrm{C}$. in spring to $10^{\circ} \mathrm{C}$. or even higher at the summer solstice; sunrise $\operatorname{limb}-20^{\circ} \mathrm{C}$. (bright phase) to $-60^{\circ} \mathrm{C}$. at opposition; sunset $\operatorname{limb}-5^{\circ}$ to $0^{\circ} \mathrm{C}$. at the terminator to $5^{\circ} \mathrm{C}$. at opposition.

Coming now to the opposition of Mars in 1926, the principal interest was in obtaining an extensive series of measurements on the east and the west limbs of the planet for comparison with the measurements of 1924, which, as just mentioned, showed that these two regions differed in temperature, the sunset edge being the warmer.

During the present opposition, when radiometric measurements were made on 15 nights extending over a period of about 4 weeks,

${ }^{23}$ Coblentz, B. S. Sci. Papers (No. 460), 18, p. 553, 1922; Coblentz and Lampland, Lowell Obs. Bul:. No. $85 ; 1925$.

24 Coblentz, B. S. Sci. Papers (No. 512), 20, p. 372; 1925. 
it was observed that, as a general rule, the morning and forenoon side of the planet were at a lower temperature than the afternoon and evening side. This was found to be true for about 85 per cent of the measurements made; the exceptions being warm dark areas on the sunrise limb, or clouds which obscured the sunset limb. The measurements which we have made in collaboration were not sufficiently prolonged to show the marked seasonal change in temperature at the south pole that were observed in 1924. Furthermore the frequent cloudiness of the limbs prevented the observation of the gradual variation in temperature with phase on the (east or sunrise) limb and the (west) terminator, which variation was observed during the oppostion of 1924; although there is some evidence that the temperature of the east and west limbs varied according to phase, as was to be expected.

The 1926 opposition occurred about a Martian month after the summer solstice (August 24) and the surface temperature at the south pole had probably risen to its maximum. The average temperature, over the whole disk, appears to be higher than observed in 1924, and the temperature differences between the center of the disk and the poles (also between the limb and the terminator) appear to be less than observed two years ago. This is probably to be expected in view of the late summer season, as compared with the last opposition which occurred about a month before the Martian summer solstice.

In the foregoing pages the radiometric measurements made on the irradiated surface of Mars during the opposition of 1926 were reduced to temperatures by three independent methods of analysis, which give concordant results showing that the temperature of the center of the disk, under a noonday sun, is up to $30^{\circ} \mathrm{C}$. or even higher. The dark areas are at a higher temperature than the bright areas. In one instance, as observed on the central meridian, the difference was $10^{\circ}$ to $15^{\circ} \mathrm{C}$.

The temperature in the south polar and south temperate regions, where it was late summer, was much higher than in the northern hemisphere, as observed during the two preceding oppositions.

As already mentioned the temperature of the sunrise limb was observed to be lower than the sunset limb. At opposition, with no clouds visible, the difference in temperature of the limbs was perhaps $10^{\circ}$ to $15^{\circ} \mathrm{C}$.

A conspicuous feature of this year's work was the frequent observation of clouds on Mars which decrease the amount of planetary radiation emitted and give apparently low temperatures. The afternoon clouds seemed denser than the morning clouds, though this was not necessarily a general condition.

The following estimates of Martian surface temperatures are given (when it was late summer on the southern hemisphere and 
when viewed on the central meridian): The south polar region -10 to $10^{\circ} \mathrm{C}$.; south temperate zone $10^{\circ}$ to $20^{\circ} \mathrm{C}$. (clouds $-10^{\circ} \mathrm{C}$.); center of the disk $20^{\circ}$ to $30^{\circ} \mathrm{C}$.; north temperate zone $5^{\circ}$ to $15^{\circ} \mathrm{C}$.; north polar region $-25^{\circ}$ to $-40^{\circ} \mathrm{C}$.; sunrise limb (after being irradiated for an hour) $-10^{\circ} \mathrm{C}$., no phase $-20^{\circ} \mathrm{C}$., clouded $-35^{\circ} \mathrm{C}$; sunset limb (terminator) $-10^{\circ} \mathrm{C}$., no phase $10^{\circ} \mathrm{C}$., clouded $-30^{\circ} \mathrm{C}$. These values are "black body" temperatures. The true temperatures would be $10^{\circ}$ to $12^{\circ} \mathrm{C}$. higher.

The observations as a whole completely verify and extend our measurements of the two preceding oppositions, showing that the surface temperature of the summer hemisphere of Mars rises considerably above the freezing point of water, which for years has been a disputed question of considerable importance in the interpretation of the visible phenomena observed on the surface of this much discussed planet.

\section{APPENDIXES}

\section{CORRECTIONS TO THE STELLAR RADIOMETRIC MEASURE- MENTS OF 1921}

Through the courtesy of the Lowell Observatory, in 1921 the stellar spectral energy distribution and stellar temperatures of 16 stars were determined by means of a newly devised method, using a series of transmission screens. ${ }^{1}$ These screens were mounted in pairs on rods and sleeves which, by rotating a lever, enabled the observer to place the screens singly or in combination in front of the thermocouple receiver. The water cell and the quartz screen were used separately. The screens used in combination were the water cell with either red, yellow, or blue glass.

Immediately after the return of the writer to the bureau, he was engaged in referee matters and part of the calculation of the stellar data had to be assigned to an assistant who was not familiar with the instrumental procedure. Hence, he did not notice an inconsistency in the observations on the star, Sirius, in which a water-cell transmission of 65 per cent (71 per cent when corrected for reflection) was deduced. Furthermore, in view of the fact that all the binary stars, examined up to that time, had, given low water-cell transmissions, the low value observed for Sirius did not appear inconsistent to the writer. However, Sirius is now found to be an exception to the rule.

From a recent checking over of these data, ${ }^{2}$ it appears that, probably through a misunderstanding of signals, ${ }^{3}$ the quartz plate and the water cell were placed simultaneously in front of the thermocouple receiver instead of only the water cell. This conclusion is arrived at from an examination of some preliminary observations using only the water cell and only the quartz cell, which data had not been considered in the previous calculations. The average galvanometer deflections (not previously calculated) for two sets of observations, with and without the water cell interposed, were 4.19 and $5.58 \mathrm{~cm}$, respectively, giving a

\footnotetext{
1 See Figure 4 of B. S. Sci. Paper (No. 438), 17, p. 736; 1922.

2 Coblentz, Amer. Astronom. Soc. Philadelphia meeting, Dec, 29, 1926; Pop. Astron., 35, p. 137; 1927.

${ }^{3}$ Which could easily happen in view of the fact that combinations of the water cell with either red, yellow, or blue glass were also used.
} 
ratio of 75.1 per cent, or 81.9 per cent when corrected for reflection of radiation from the windows of the water cell.

Subsequently, using the complete series of screens (for example, water cell; quartz; water cell+red glass, also yellow glass), the galvanometer deflections for "no cell" and through the quartz screen were 11 to 12 per cent higher $(6.4 \mathrm{~cm}$ and $5.7 \mathrm{~cm}$, respectively), whereas the deflection observed when the water cell was interposed remained unchanged $(4.21 \mathrm{~cm})$ which could occur only from poor focusing or the presence of the quartz screen. Correcting the value $(4.21 \mathrm{~cm})$ by 9 per cent for the presence of the quartz screen gives $4.58 \mathrm{~cm}$ which is then consistent with the other observations. This gives a water cell transmission of $(4.58 \div 6.4)=71.8$ per cent, or 78.5 per cent when corrected as usual for reflection from the water cell. If we ascribe the discrepancy to poor focusing and correct the observed deflection (4.21) by 12 per cent, as indicated by the measurements of "no cell" and through the quartz plate, the W. C. T. $=80.5$ per cent, which is in good agreement with the preceding value.

Using this same radiometric equipment, during the spring of 1925 and again during the fall of 1926, C. O. Lampland obtained an extensive series of (unpublished) measurements of Sirius, all of which are in agreement in giving water-cell transmissions which are higher than 80 per cent, as previously observed by the writer on A-type stars.

From the foregoing discussion, it is evident that, contrary to other binaries observed, the companion star of Sirius contributes but little to the infra-red radiation of the primary star. The conclusions of Coblentz and Lampland 4 that the companion star of Sirius is type $K$ must, therefore, be withdrawn; and if the radiometric measurements permit any interpretation, it is that the companion star is close to type A, which is the classification assigned from spectroscopic evidence. ${ }^{5}$

The revision of the water-cell transmission data has but little effect upon the temperature estimates previously published; because those values were obtained from a consideration of the data obtained with all the screens.

Of the other stars examined, the temperature estimates of the type B stars ( $\beta$ and $\epsilon$ Orionis) might be raised by $1,000^{\circ}$ or $2,000^{\circ}$ C., though the method of calculation for this type of 'star hardly permits of great refinements.

\section{SUPPLEMENTAL DATA ON PLANETARY RADIATION AND SELECTIVE REFLECTION OF MARS}

In order to abbreviate our report ${ }^{6}$ of the observations on Mars, made in 1924, some interesting and important data were omitted. These data deal with the question of the relative amounts of the incoming planetary and solar radiation, the outgoing ("nocturnal") radiation from the thermopile, and especially the selective absorption and reflection of the solar radiation by the planet.

The thermopile is usually of symmetrical construction so that the loss of nocturnal radiation from it need not be considered. In the calculations of planetary temperatures from the water-cell transmissions, it is assumed that there is no marked selective absorption or reflection of solar radiation by the planet. Hence, if the water-cell transmission of the radiation from the planet is not the same as that of direct solar radiation, it is assumed that this is owing to the presence of planetary radiation. The water cell is, therefore, apparently

4 Coblentz and Lampland, J. Frank. Inst., 199, p. 790; 1925.

5 Adams, Publ. Astronom. Soc. Pacific, 27, p. 236; 1915.

6 Coblentz and Lampland, J, Frank. Inst., 199, p. 785; 200, p. 103; 1925. 
a quick means of determing whether the planet is sufficiently heated to emit perceptible radiation. This is evident from the following equation: $\mathrm{j}$.

$$
T=\frac{S^{\prime}}{S+(P-N)}
$$

where $S$ represents the intensity of the total incoming solar radiation reflected by the planet, $S^{\prime}$ is the intensity of this solar radiation transmitted through the water cell, $P$ is the incoming planetary radiation emitted by the planet and $N$ is the outgoing nocturnal radiation emitted by the thermocouple receiver. The magnitude of the transmission $T$, through the water cell, will depend upon the question whether $P$ is (1) greater than, (2) equal to, or (3) less than $N$. For a symmetrical thermocouple having the two receivers exposed to the sky $N=O$. If the planetary radiation is perceptible then the per cent transmission through the water cell, after correction for reflection will be lower than that (viz, $S^{\prime} \div S=75.5$ per cent) observed for direct solar radiation; but the water-cell transmission might be lower than 75.5 per cent if there is selective absorption of solar radiation of wave lengths less than $1.4 \mu$ relative to the radiation of wave lengths at $1.4 \mu$ to $8 \mu$.

This question could have been studied by using a vacuum thermopile having a glass window. The measurements of the water-cell transmissions were made with vacuum thermocouple mounting No. 11, couple No. 2 (diameter of receiver $0.23 \mathrm{~mm}$ ), at the 53.3 -foot focus of the great reflector by temporarily placing the glass screen of thickness $0.158 \mathrm{~mm}$ (or the fluorite screen) in front of the rock-salt window and observing the galvanometer deflection with and without the water cell intervening. Thermocouple No. 2 in mounting No. 13 was used in a similar manner at the 18 -foot focus.

As a further test, using the 53.3-foot focus, the radiative properties of the receivers of thermocouple No. 1 in vacuum mounting No. 13 were rendered unsymmetrical by mounting a small-sized ( 5 by 3 by $0.91 \mathrm{~mm}$ ) glass plate inside of the vacuum chamber, about $2 \mathrm{~mm}$ in front of one of the receivers. The glass plate shielded this receiver from exchanges of planetary and nocturnal radiation. This, of course, caused a shift of the zero reading of the galvanometer scale which was adjusted by means of the control magnets. The water-cell transmission measurements were obtained by exposing these thermocouple receivers in the usual manner to the radiation incident through the rock-salt window.

The results of these measurements are given in Table 6. It may be noted that in all cases, whether the temporary window was of glass, or of fluorite which transmitted some planetary radiation, the water-cell (also glass-screen) transmissions are higher than when planetary radiation is transmitted through the rock-salt window. 
TABLE 6.-Percentage transmission through a 1 -cm screen of water, or thin $(0.158$ $\mathrm{mm}$ ) glass, using a radiometer window of rock salt, of glass, and of fluorite

[All data corrected for reflection losses at the surfaces of the screens]

\begin{tabular}{|c|c|c|c|c|c|}
\hline Object & \multirow{2}{*}{ Screen } & \multicolumn{3}{|c|}{ Window } & \multirow{2}{*}{ Remarks } \\
\hline Date, 1924. M. S. T. & & Rock salt & Glass & Fluorite & \\
\hline \multirow{2}{*}{\multicolumn{6}{|c|}{$\begin{array}{l}\text { Mars: } \\
\text { June } 25,3.40 \text { a. m...- Water- }\end{array}$}} \\
\hline & Water- & $\begin{array}{l}38.8 \\
30.8\end{array}$ & 613 & 51.1 & $\begin{array}{l}\text { Vacuum mounting No. } 13 . \\
\text { Vacuum mounting }\end{array}$ \\
\hline & Glass & $\begin{array}{l}30.8 \\
52.0\end{array}$ & 61.3 & 71.7 & $\begin{array}{l}\text { Vacuum mounting No. } 11 . \\
\text { Do. }\end{array}$ \\
\hline $15,1.30$ a. m. & Water. & 32.4 & 57.8 & & \\
\hline $1.50 \mathrm{a} . \mathrm{m}$ & Glass.. & 52.5 & & 79.3 & Do. \\
\hline 16. $12.15 \mathrm{a} . \mathrm{m}_{-}$ & Water. & 33.0 & 47.3 & & $\begin{array}{l}\text { Vacuum mounting No. } 13 \text {, right- } \\
\text { hand receiver of thermocouple } \\
\text { No. } 1 \text {, covered with glass. }\end{array}$ \\
\hline Venus: $\quad 18,2.05$ a. m.... & ...do_ & 31.3 & 59.2 & & Vacuum mounting No. 11 \\
\hline Sept. $1,6.45$ a. m. & ...do & 63.5 & 70.8 & & Do. \\
\hline $\begin{array}{l}\text { Moon: } \\
\text { Aug. } 15,12.30 \text { a. m... }\end{array}$ & ...-do & 24.1 & 48.8 & & Do. \\
\hline Jupiter: $20,2.15$ a. m... & -..do. & 15.5 & 49.8 & & Do. \\
\hline $\begin{array}{l}\text { Aug. } 16,8.30 \text { p. m... } \\
\text { Mount Agassiz: }\end{array}$ & ....do_ & 74.8 & 78.3 & & Do. \\
\hline June $25,2.14$ p. m.- & ....do.. & 117.0 & & & Data are not corrected for noctur- \\
\hline $\begin{array}{l}\text { Turkey Mountain: } \\
\text { June } 25,2.30 \text { p. m... }\end{array}$ & -..do. & 85.0 & & & $\begin{array}{l}\text { Data are not corrected for excess } \\
\text { radiation from thermopile. }\end{array}$ \\
\hline
\end{tabular}

In the measurements on Mars, when the glass screen was placed in front of the thermocouple receiver to eliminate the planetary radiation the water-cell transmission should have been about 75.5 per cent, if the spectral energy distribution of the radiation transmitted through the water cell is closely that of the direct solar radiation.

On August 14, the water-cell transmission was 61.3 per cent when using the glass window, from which it follows that the radiation of wave lengths $1.4 \mu$ to $8 \mu$ was 38.7 per cent. If the radiation had been a pure solar spectral distribution, the component at $1.4 \mu$ to $8 \mu$ would have been $(61.3 \times 0.322=) 19.7$ per cent. This leaves an unaccounted difference of $(38.7-19.7=) 19.0$ per cent for planetary radiation.

But other measurements ${ }^{7}$ through the rock-salt window and quartz screen show that only 11.2 per cent of the total is planetary radiation of wave lengths $1.4 \mu$ to $8 \mu$ against 19.0 per cent by this analysis. From this, it appears that there is selective absorption and reflection in the spectral region of wave lengths less than $4 \mu$, which modifies the solar spectral energy distribution.

Further evidence of the selective depletion of solar radiation is shown in Table 6 where there is a systematic variation in the water-cell transmissions of the radiation through the rock salt and the glass windows. As the water-cell transmissions increase for the former they decrease for the latter. When using the rock-salt window, the water-cell transmission was the highest (33.0 per cent, planetary radiation the lowest) on August 16, while the transmission through the glass window was the lowest, 47.3 per cent, instead of rising in value toward 75.5 per cent. Evidently there is some modification of the solar spectral energy distribution at $0.3 \mu$ to $1.4 \mu$ relative to that at $1.4 \mu$ to $8 \mu$ on reflection from Mars. The red and infra-red radiation of wave lengths greater than $1.4 \mu$ is relatively

7 Coblentz and Lampland, J Frank. Inst., 200, p. 104; 1925, Table 4. 
stronger than the radiation of wave lengths less than $1.4 \mu$. This is in harmony with the visual observations; for Mars is known as a "red" planet.

This information will be of interest in future calculations of planetary temperatures by the method of total radiation using the water-cell transmissions. It may account for some of the deviations in the temperature calculations by this method as compared with the other methods. It shows the importance of deducing temperatures by as many methods as are available, no matter how superior any one method may appear. For this reason our aim has been to use a variety of methods of estimating planetary temperatures.

In view of the fact that Menzel's ${ }^{8}$ calculations indicated a surface temperature of $-110^{\circ} \mathrm{C}$., for Jupiter and Saturn, it was of especial interest to make the measurements through the glass window. Unfortunately, at the time of making the measurements, Saturn was already too low on the horizon and the intensity would have been too low for accurate measurement with the 53.3-foot focus.

The measurements of August 16 on Jupiter, using the 53.3-foot focus are instructive. Three series of measurements of water-cell transmissions gave an average value of 74.8 per cent, observed through the rock-salt window. Three similar water-cell transmissions, observed through the glass window gave an average transmission of 78.3 per cent. These transmissions are so closely the same that evidently there is but little incoming planetary radiation. Furthermore, the spectral energy distribution of the solar radiation is practically unmodified by reflection from the atmosphere of Jupiter. The infra-red component at $1.4 \mu$ to $8 \mu$ may, perhaps, suffer greater absorption relatively to the component at 0.3 to $1.4 \mu$, which is to be expected on the basis of scattering by gases and of internal reflection of molecules of water vapor.

In contrast with the measurements on Jupiter are those on the moon and on Mars in which the ratio of the water-cell transmissions, observed through the rock salt and the glass windows are as $1: 2$. This seems significant in view of the fact that the temperature of the surface of the moon is admittedly much above $0^{\circ}$ C., and by inference one seems forced to the conclusion that a similar condition exists on Mars.

From equation (1), it is evident that a heating (or cooling if necessary) device can be provided so that the radiation exchange will be $P=N$ and an estimate obtained of the temperature of the planet. Or a shutter or an auxiliary radiator can be provided and its temperature varied as used long ago by Langley, and by Very in their measurements of the radiation and temperature of the moon.

In concluding this discussion, it is of interest to mention some observations which were made on terrestrial sources, using a regular laboratory thermopile in which only the central (circular) receiver was exposed to the surroundings. Hence, if the shutter does not have exactly the same temperature as the background, then, on opening the shutter, there is an emission of nocturnal, $N$, radiation from the thermopile. This is evident from the data in Table 6 which were obtained in connection with the measurements on terrestrial sources described in the preceding paper. ${ }^{9}$ The measurements show what appears to be an outgoing radiation from the thermopile. In this case, the nocturnal radiation, and presumably the temperature, of Mount Agassiz and of Turkey Mountain (which was low on the horizon) had decreased to less than that emitted by the thermopile and $P$ was less than $N$ (equation (1)). In the measurement on Mount Agassiz (the forest area described in the previous paper) the outgoing radiation from the thermopile was so great that the apparent intensity of the incoming radiation

8 Menzel, Astrophys. J., 58,p. 65; 1923.

- Coblentz and Lampland, J. Frank. Inst., 199, p. 785; 1925. 
was greater $(9.0 \mathrm{~cm})$ through the water cell, which prevented an exchange of $P$ and $N$, than the value $(7.7 \mathrm{~cm})$ observed without the water cell.

\section{WATER-CELL TRANSMISSIONS OF SOLAR RADIATION}

The importance of using a symmetrical radiometer, or of determining the loss of nocturnal radiation when using an unsymmetrical radiometer for making transmission measurements at high altitudes, when sighting on the sky at altitudes greater than about $30^{\circ}$ is evident from the following experiments.

Measurements made by Coblentz and Hughes at sea level (Washington) at the noon hour on May 25 and June 28, 1926, using a thermocouple with but one receiver exposed to the sky, gave a water-cell transmission of solar radiation amounting, respectively, to 78.0 and 79.8 per cent. These high values are owing to the great humidity which absorbs the infra-red radiation. Measurements made with the quartz screen $(t=2.85 \mathrm{~mm})$ gave no evidence of nocturnal radiation from the thermopile to the sky.

Measurements made by Coblentz and Lampland at the Lowell observatory (elevation 7,250 feet) using this same thermocouple showed an appreciable loss of nocturnal radiation from the thermopile to the sky. The solar radiation intensity was constant to less than 0.5 per cent for two hours at noon. The galvanometer deflection observed through the quartz screen (after making a correction of 8.5 per cent for reflection and 0.6 per cent for solar radiation of wave lengths greater than $4 \mu$ ) was larger than that observed without the plate. The loss of nocturnal radiation from the thermocouple (which was in air, but covered with a fluorite window) to the sky on September 30, October 4 and 16, 1926, was, respectively, 3,4 , and 2.3 per cent of the total incident solar radiation. The low value on October 16 was owing to slight smokiness from a small forest fire.

The water-cell transmissions on these dates (when corrected for nocturnal radiation from the thermocouple and reflection from the water cell) were 77.0, 76.9, and 76.3 per cent. On October 4 measurements at 11.30 a. $\mathrm{m}$. and 1.40 p. $\mathrm{m}$. gave transmissions of 76.8 and 77.1 per cent, respectively.

These water-cell transmissions are about 2 per cent higher than the value (75.5 per cent) obtained on June 17, 1922, which value is used in the calculation of planetary temperatures using the fourth power law of total radiation. ${ }^{10}$

The value, 75.5, is based upon 5 sets of measurements made at 11.15 to 11.50 a. m., giving a mean value of 75.4 per cent, and 5 sets of observations made at 4.05 to $4.25 \mathrm{p}$. m., giving a mean value of 75.8. In view of the fact that the measurements were made (in the same manner as the planetary observations) after two reflections from silvered mirrors, which selectively absorb the short wave lengths, the water-cell transmission should be lower than that observed when this same thermocouple was exposed directly to the sun.

The fact that no correction was necessary for loss of nocturnal radiation from the thermocouple receiver to the sky is probably owing to the use of a small ( 4 by $4 \mathrm{~cm}$ ) plane mirror in place of the great reflector which was exposed to the sun through a small opening in the cover over the end of the telescope tube. In this manner the thermocouple could radiate to only a very small portion of the sky. After correcting the galvanometer deflections observed through the quartz plate by 8.5 per cent for losses by reflection the values were from 0.5 to 0.8 per cent smaller than the deflection for the unobstructed solar radiation. This was considered to be due to the presence of solar radiation of wave lengths greater

${ }_{10}$ Coblentz, B. S. Sci. Papers (No. 460), 18, p. 535; 1922; Coblentz and Lampland, Lowell Obs. Bull., $85 ; 1925$. 
than $4 \mu$, which is in agreement with the spectral energy measurements of Fowle 11 at $8 \mu$ to $15 \mu$. If there was any loss of nocturnal radiation from the thermocouple receiver as used in these measurements, it was less than 0.5 per cent of the total incident radiation. A careful reexamination of these observations shows that the value 75.5 per cent could not be decreased to less than 75.1 per cent, which decrease would not affect our temperature estimates sufficiently to demand revision. This value, which was obtained at noon and at $4 \mathrm{p}$. m., includes the altitudes at (the air mass through) which the planetary observations were usually made; which question has been mentioned bv Menzel. ${ }^{12}$

WASHINGTON, January 25, 1927.

11 Fowle, Smithsonian Miscell. Coll., 68, p. 41; 1917.

12 Menzel, Publ. Astr. Soc. Pac., 39, p. 26; 1927. 